\title{
Water flow through sediments and at the ice-sediment interface beneath Sermeq Kujalleq (Store Glacier), Greenland
}

\section{Article \\ *Present address: Alfred Wegener Institute, Helmholtz Centre for Polar and Marine Research, Bremerhaven, Germany \\ †Present address: Byrd Polar \& Climate Research Center, The Ohio State University, 1090 Carmack Rd, Columbus, Ohio 43210}

Cite this article: Doyle $\mathrm{SH}$, Hubbard B, Christoffersen P, Law R, Hewitt DR, Neufeld JA Schoonman CM, Chudley TR, Bougamont M (2021). Water flow through sediments and at the ice-sediment interface beneath Sermeq Kujalleq (Store Glacier), Greenland. Journal of Glaciology 1-20. https://doi.org/10.1017/ jog.2021.121

Received: 25 June 2021

Revised: 20 October 2021

Accepted: 21 October 2021

Author for correspondence:

Samuel Doyle, E-mail: sdd08@aber.ac.uk

\author{
Samuel H. Doyle ${ }^{1}$ (D), Bryn Hubbard ${ }^{1}$ (D), Poul Christoffersen² (D), Robert Law ${ }^{2}$, \\ Duncan R. Hewitt ${ }^{3}$, Jerome A. Neufeld ${ }^{4,5,6}$, Charlotte M. Schoonmann ${ }^{2, \star}$, \\ Thomas R. Chudley $2, \dagger$ (D) and Marion Bougamont ${ }^{2}$
}

${ }^{1}$ Centre for Glaciology, Department of Geography and Earth Sciences, Aberystwyth University, Aberystwyth, SY23 3DB, UK; ${ }^{2}$ Scott Polar Research Institute, Cambridge University, Cambridge, CB2 1ER, UK; ${ }^{3}$ Department of Mathematics, University College London, 25 Gordon Street, London, WC1H OAY; ${ }^{4}$ Institute of Theoretical Geophysics, Department of Applied Mathematics and Theoretical Physics, University of Cambridge, Wilberforce Road, Cambridge CB3 OWA, UK; ${ }^{5}$ BP Institute, University of Cambridge, Madingley Rise, Cambridge CB3 0EZ, UK and ${ }^{6}$ Department of Earth Sciences, Bullard Laboratories, University of Cambridge, Madingley Rise, Cambridge CB3 OEZ, UK

\begin{abstract}
Subglacial hydrology modulates basal motion but remains poorly constrained, particularly for soft-bedded Greenlandic outlet glaciers. Here, we report detailed measurements of the response of subglacial water pressure to the connection and drainage of adjacent water-filled boreholes drilled through kilometre-thick ice on Sermeq Kujalleq (Store Glacier). These measurements provide evidence for gap opening at the ice-sediment interface, Darcian flow through the sediment layer, and the forcing of water pressure in hydraulically-isolated cavities by stress transfer. We observed a small pressure drop followed by a large pressure rise in response to the connection of an adjacent borehole, consistent with the propagation of a flexural wave within the ice and underlying deformable sediment. We interpret the delayed pressure rise as evidence of no pre-existing conduit and the progressive decrease in hydraulic transmissivity as the closure of a narrow $(<1.5 \mathrm{~mm})$ gap opened at the ice-sediment interface, and a reversion to Darcian flow through the sediment layer with a hydraulic conductivity of $\leq 10^{-6} \mathrm{~m} \mathrm{~s}^{-1}$. We suggest that gap opening at the ice-sediment interface deserves further attention as it will occur naturally in response to the rapid pressurisation of water at the bed.
\end{abstract}

\section{Introduction}

A list of symbols is presented in Appendix A.

The nature of subglacial hydrology and basal motion on ice masses underlain by soft sediments are central questions in ice dynamics (e.g., Clarke, 1987; Murray, 1997; Tulaczyk and others, 2000). However, despite abundant evidence for subglacial sediments beneath fast-moving outlet glaciers and ice streams draining the Greenland and Antarctic ice sheets (e.g., Alley and others, 1986; Blankenship and others, 1986; Christianson and others, 2014) and mountain glaciers (e.g., Humphrey and others, 1993; Iverson and others, 1995), softbedded processes remain poorly constrained (Walter and others, 2014; Alley and others, 2019). Water flow in a soft-bedded subglacial environment has been hypothesised to occur via: Darcian flow through permeable sediments (Clarke, 1987); sheet flow at the ice-sediment interface (e.g., Weertman, 1970; Alley and others, 1986; Flowers and Clarke, 2002; Creyts and Schoof, 2009); and concentrated flow in channels cut into the ice, and canals eroded into the sediment (Walder and Fowler, 1994; Ng, 2000). Drainage through gaps opened and closed dynamically at the ice-sediment interface by turbulent water flow at high pressure has also been proposed as an explanation for the rapid drainage of boreholes (Engelhardt and Kamb, 1997; Kamb, 2001) and both supra- and pro-glacial lakes (Sugiyama and others, 2008; Tsai and Rice, 2010, 2012; Hewitt and others, 2018). Direct evidence for gap-opening at the ice-sediment interface is limited to three observational studies (Engelhardt and Kamb, 1997; Lüthi, 1999; Iverson and others, 2007). However, despite support from detailed analytical modelling (Schoof and others, 2012; Rada and Schoof, 2018) dynamic gap opening has yet to be fully developed for larger-scale numerical models of subglacial hydrology.

The water-saturated sediment layer beneath a soft-bedded ice mass can be approximated as an aquifer confined by an overlying ice aquiclude (e.g., Lingle and Brown, 1987; Stone and Clarke, 1993). And, with careful adaptation, standard hydrogeological techniques can be used to estimate subglacial aquifer properties such as transmissivity, conductivity, diffusivity and storativity. These include slug tests, where the borehole water level is perturbed by the insertion and sudden removal of a sealed pipe of known volume (Hodge, 1979; Stone and Clarke, 1993; Iken and others, 1996; Kulessa and Hubbard, 1997; Stone and others, 1997; Kulessa and Murray, 2003; Kulessa and others, 2005), packer tests where the borehole is sealed near the surface and subsequently rapidly pressurised with air (Stone and Clarke, 1993; Stone and others, 1997), and pumping tests where the borehole hydraulic head is monitored in 
response to water injection or extraction (e.g., Engelhardt, 1978; Engelhardt and Kamb, 1997; Iken and Bindschadler, 1986; Lüthi, 1999). Borehole drainage on connection with the bed (hereafter 'breakthrough'), and the recovery to equilibrium water levels have also been used to determine subglacial aquifer properties (e.g., Stone and Clarke, 1993; Engelhardt and Kamb, 1997; Stone and others, 1997; Lüthi, 1999). During breakthrough events the water level in the initially water-full borehole either: (i) drops rapidly to a new equilibrium level some tens of metres below the surface, (ii) does not drop at all, or (iii) drops slowly, or rapidly, to a new equilibrium level after a delay of minutes to days, with the variability in response usually explained in terms of the connectivity of the subglacial drainage system (e.g., Smart, 1996; Gordon and others, 2001). The hydraulic conductivity of a subglacial sediment layer has also been derived from the propagation and attenuation of diurnal subglacial water pressure waves (e.g., Hubbard and others, 1995), and from numerical modelling of the pressure peaks induced when pressure sensors freeze in (Waddington and Clarke, 1995). To date, the application of borehole response tests to marine-terminating glaciers in Greenland is limited to a single study (Lüthi, 1999), presumably due to the challenges of adapting groundwater techniques to the ice-sheet setting.

The application of hydrogeological techniques requires a number of simplifying assumptions. Many techniques are fundamentally based on Darcian flow and inherently assume that the aquifer is isotropic and homogeneous; conditions that may rarely be met in the subglacial environment. Water flow in groundwater investigations is typically slow and assumed to be Darcian. While this may hold for low-velocity water flow through subglacial sediments, the discharge rates during borehole breakthrough events mean turbulent flow is likely in the vicinity of the borehole base (e.g., Stone and Clarke, 1993). Further complications arise due to the greater density of water than ice, overpressurising the ice at the base of water-filled glacier boreholes with the potential to raise the ice from its substrate permitting water to flow through the gap created. (Overpressure here being water pressure in excess of the ice overburden pressure). Previous studies have attempted to determine the widths of such gaps (Weertman, 1970; Engelhardt and Kamb, 1997; Lüthi, 1999; Iverson and others, 2007).

Ice boreholes provide direct access to the subglacial environment allowing sensor installation and borehole response tests. Here, we analyse borehole response tests conducted on Sermeq Kujalleq (Store Glacier) in West Greenland during summer 2019. The response tests included breakthrough events, which occurred consistently when boreholes intersected the icesediment interface, constant-rate pumping tests undertaken as water was pumped into the borehole as the drill stem was raised to the surface, and recovery tests following removal of the stem. The results provide insights into subglacial hydrological conditions and permit estimation of the hydraulic transmissivity and conductivity of the subglacial drainage system.

\section{Methods}

\subsection{Field site}

Sermeq Kujalleq (Store Glacier) is a major fast-moving outlet glacier of the Greenland Ice Sheet draining an $\sim 34,000 \mathrm{~km}^{2}$ catchment area (Rignot and others, 2008) into Ikerasak Fjord - a tributary of Uummannaq Fjord. (Note that as several glaciers share the same name - and for continuity with previous literature - we give the English glacier name in brackets after the official Greenlandic name.) In summer 2019, we used pressurised hot water to drill seven boreholes on Sermeq Kujalleq (Store Glacier) at site R30 (N70 34.0', W050 5.2') located in the centre of the drained bed of supraglacial lake L028 (Fig. 1a; Table S1).
R30 lies $30 \mathrm{~km}$ from the calving front at $863 \mathrm{~m}$ a.s.l. and is within the ablation area; there was no winter snow or firn present during the drilling campaign. Ice flow measured by a Global Navigation Satellite System (GNSS) receiver averaged $521 \mathrm{~m} \mathrm{a}^{-1}$ in the SSW direction (217 ${ }^{\circ}$ True) between 9 July and 16 September 2019. The surface slope was calculated as $1.0^{\circ}$ from linear regression of the ArcticDEM digital elevation model (Porter and others, 2018) over a distance of ten ice thicknesses $(10 \mathrm{~km})$. Lake L028 drained via hydraulic fracture on 31 May 2019 (Chudley and others, 2019b) forming two major moulins (each of diameter $\sim 6 \mathrm{~m}$ ) located within $200 \mathrm{~m}$ of the drill site (Fig. 1b). Boreholebased Distributed Acoustic Sensing (DAS) in BH19c provides evidence for up to $37 \mathrm{~m}$ of consolidated subglacial sediment at R30 (Booth and others, 2020), while seismic reflection surveys at site S30 (8 km to the south-east of R30; Fig. 1a) revealed up to 45 $\mathrm{m}$ of unconsolidated sediment overlying consolidated sediment (Hofstede and others, 2018). Borehole-based investigations of englacial and basal conditions at S30 reported low effective pressures $(180-280 \mathrm{kPa})$, an absent or thin $(<10 \mathrm{~m})$ basal temperate ice layer, and internal deformation concentrated within the lowermost $100 \mathrm{~m}$ of ice, below the transition between interglacial (Holocene) and last-glacial (Wisconsin) ice (LGIT; Doyle and others, 2018; Young and others, 2019). At R30, Distributed Temperature Sensing (DTS) reveals a $70 \mathrm{~m}$-thick basal temperate ice layer, the LGIT at $889 \mathrm{~m}$ depth and a steeply curving temperature profile with a minimum ice temperature of $-21.1^{\circ} \mathrm{C}$ near the centre of the ice column (Law and others, 2021).

\subsection{Hot water drilling}

Boreholes were drilled using a hot water drill system similar to that described in Makinson and Anker (2014). Pressurised, hot water $\left(11.0 \mathrm{MPa} ; \sim 80^{\circ} \mathrm{C}\right)$ was provided by five pressure-heater units (Kärcher HDS1000DE) at a regulated flow rate of 751 $\min ^{-1}$, through a $1,350 \mathrm{~m}$ long, $19.3 \mathrm{~mm}\left(0.75^{\prime}\right)$ bore hose. A load cell and rotary encoder recorded the load on the drill tower and the hose length below the surface at $0.5 \mathrm{~Hz}$ with a resolution of $1 \mathrm{~kg}$ and $0.1 \mathrm{~m}$, respectively (Figs S1-S3). Borehole logging to a depth of $325 \mathrm{~m}$ indicates that the hot water drilling system consistently drills boreholes that are within $1^{\circ}$ of vertical (Hubbard and others, 2021).

Boreholes $(\mathrm{BH})$ were named by year and by letter in chronological order of drilling, with $\mathrm{BH} 19 \mathrm{a}$ the first borehole drilled in 2019 (Table S1). Boreholes were drilled in two clusters with the first (BH19a, b, c and d) separated from the second (BH19e, f and g) by $70 \mathrm{~m}$ (Fig. 1b). Seven boreholes were drilled in 2019 with three reaching the ice-sediment interface at depths of $1,043 \mathrm{~m}$ (BH19c), 1,022 $\mathrm{m}$ (BH19e) and 1,039 $\mathrm{m}$ (BH19g), giving a mean ice thickness of $1,035 \mathrm{~m}$ and a mean elevation of the glacier sole of $-172 \mathrm{~m}$ a.s.l. (Table 1). Four boreholes were terminated above the ice-sediment interface (see Table S1). Prior to breakthrough boreholes were water-filled to the bare ice surface, with excess water supplied by the pressure-heater units overflowing from the top of the borehole.

To reduce overall drilling duration and produce a more uniform borehole radius $(0.06 \mathrm{~m}$ four hours after termination of drilling), we optimised drilling speed using the numerical borehole model of Greenler and others (2014). The borehole model was constrained by ice temperature from site R29, $1.1 \mathrm{~km}$ distant (Hubbard and others, 2021, Fig. 1a), and a hose thermal conductivity of $0.24 \mathrm{~W} \mathrm{~m}^{-1} \mathrm{~K}^{-1}$. Borehole radius at the time of breakthrough was then estimated by re-running the model with the recorded drill speeds and the equilibrated ice temperature profile measured in BH19c at site R30 (Law and others, 2021). The mean borehole radius for $\mathrm{BH} 19 \mathrm{c}, \mathrm{BH} 19 \mathrm{e}$ and $\mathrm{BH} 19 \mathrm{~g}$ output by the model at the time of borehole breakthrough was $0.07 \mathrm{~m}$, with 


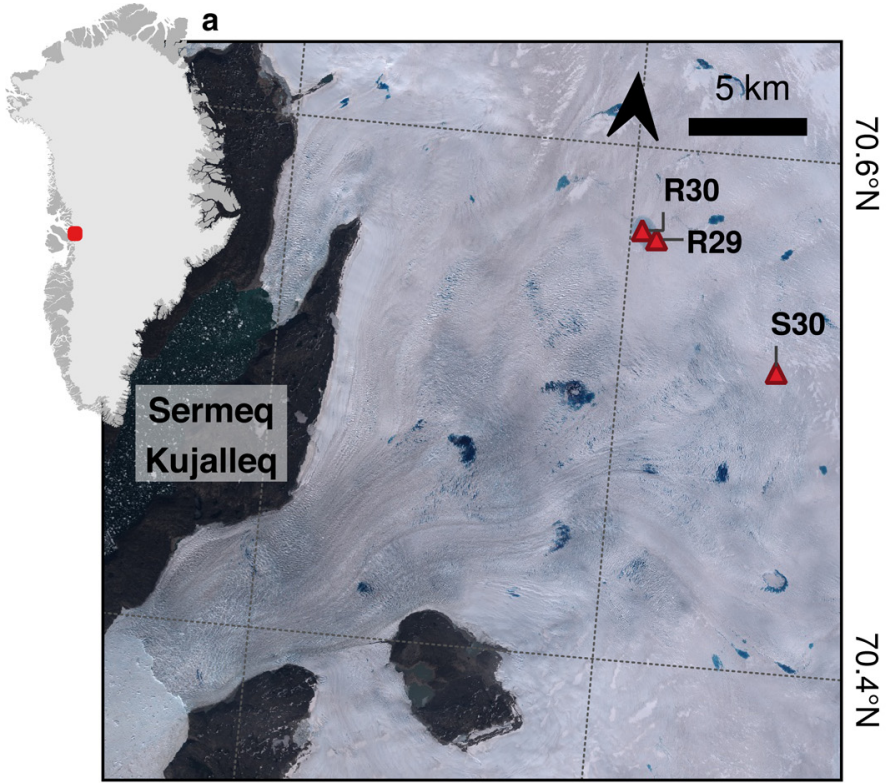

$50.5^{\circ} \mathrm{W}$

$50.1^{\circ} \mathrm{W}$

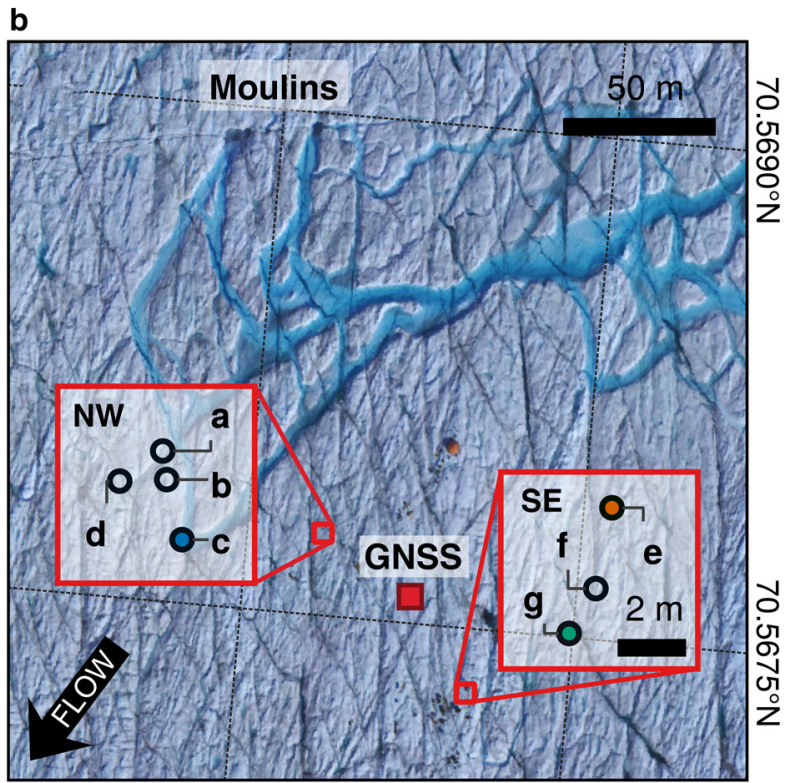

$50.0880^{\circ} \mathrm{W}$

$50.0850^{\circ} \mathrm{W}$

Fig. 1. Maps of the field site. (a) Location of the study site R30 on Sermeq Kujalleq (Store Glacier) with the location of the R29 and S30 drill sites also marked. The background is a Sentinel-2 image acquired on 1 June 2019 and the red square on the inset map shows the location in Greenland. (b) Close up of the R30 study site showing the location of boreholes, moulins and the GNSS receiver. Three boreholes intersected the ice-sediment interface (filled, colour-coded circles) and four terminated above the base (hollow circles). The background orthophoto was acquired by an uncrewed aerial vehicle survey following Chudley and others (2019) on 21 July 2019.

Table 1. Key data for the boreholes that reached the bed. Variables $h_{0}, p_{\mathrm{w}}$, and $N$ were calculated for the reference period $36-60 \mathrm{~h}$ after each respective breakthrough, which was deemed representative of subglacial water pressure. A list of symbols is presented in Appendix A.

\begin{tabular}{|c|c|c|c|c|}
\hline & $\mathrm{BH} 19 \mathrm{C}$ & $\mathrm{BH} 19 \mathrm{e}$ & $\mathrm{BH} 19 \mathrm{~g}$ & Mean \\
\hline Ice thickness (m) & $1,043.0$ & $1,022.3$ & $1,039.2$ & $1,034.8$ \\
\hline Piezometer offset (m) & 0.05 & 0.1 & 0.4 & 0.18 \\
\hline Piezometer orthometric height ( $m$ a.s.l.) & -180.5 & -159.6 & -175.1 & -171.7 \\
\hline Water-full overpressure $(\mathrm{kPa})$ & $921 \pm 102$ & $902 \pm 100$ & $917 \pm 102$ & $913 \pm 101$ \\
\hline Breakthrough time (UTC) & 5 July 2019 02:54:36 & 12 July 2019 03:39:35 & 22 July 2019 08:07:23 & $\mathrm{n} / \mathrm{a}$ \\
\hline Breakthrough volume $\left(\mathrm{m}^{3}\right)$ & 4.83 & 4.50 & 4.93 & 4.75 \\
\hline Peak load (kg) & 199 & 180 & 214 & 198 \\
\hline Drill-indicated breakthrough depth ${ }^{a}(\mathrm{~m})$ & 1031.0 & 1010.5 & 1017.3 & 1019.6 \\
\hline Drill-indicated maximum depth ${ }^{a}(\mathrm{~m})$ & 1031.0 & 1013.3 & 1017.4 & 1020.6 \\
\hline Pump rate $\left(\mathrm{l} \mathrm{min}^{-1}\right)$ & 75 & 75 & 75 & 75 \\
\hline Pumping duration during raise (min) & 140 & 140 & 118 & 133 \\
\hline Volume of water pumped during raise $\left(\mathrm{m}^{3}\right)$ & 10.5 & 10.5 & 8.9 & 10.0 \\
\hline Recovery time (h) & 36.4 & 49.7 & 45.4 & 43.8 \\
\hline Initial water level depth (m) & 78.1 & 72.9 & 79.8 & 76.9 \\
\hline$h_{0}(\mathrm{~m})$ & 773.0 & 777.1 & $775.9^{b}$ & 775.3 \\
\hline$p_{\mathrm{i}}(\mathrm{MPa})$ & $9.310 \pm 0.1$ & $9.125 \pm 0.1$ & $9.276 \pm 0.1$ & $9.237 \pm 0.1$ \\
\hline$p_{\mathrm{w}}(\mathrm{MPa})$ & 9.352 & 9.178 & $9.166^{b}$ & 9.232 \\
\hline$p_{\mathrm{w}}\left(\%\right.$ of $\left.p_{\mathrm{i}}\right)$ & $100.5 \pm 1.1$ & $100.6 \pm 1.1$ & $100.5 \pm 1.1^{b}$ & $100.5 \pm 1.1$ \\
\hline$N(\mathrm{kPa})$ & $-43 \pm 102$ & $-54 \pm 102$ & $-42 \pm 102^{b}$ & $-46 \pm 102$ \\
\hline
\end{tabular}

${ }^{a}$ Drill-indicated depths do not account for the elastic extension of the hose under load.

${ }^{b}$ Recorded in $\mathrm{BH} 19 \mathrm{e}$ due to freeze-in of pressure transducer in BH19g.

larger radii (mean of $0.10 \mathrm{~m}$ ) in the lowermost $100 \mathrm{~m}$ of the ice column (Table A1) due to intentionally slower drilling as the drill approached the ice-sediment interface, together with the presence of temperate ice that was unaccounted for during initial model runs. The borehole model underestimated the near-surface (i.e. $0-100 \mathrm{~m}$ ) borehole radius $\left(r_{\mathrm{s}}\right)$, possibly due to turbulent heat exchange that is not included in the model, so we use the radius at the water line calculated for $\mathrm{BH} 19 \mathrm{~g}(0.14 \mathrm{~m})$ as $r_{\mathrm{s}}$ for all the borehole response tests (see Appendix B).

Analysis of the temperature time series recorded by DTS in BH19c (Law and others, 2021) shows that the boreholes rapidly froze shut. At $580 \mathrm{~m}$ depth, where the undisturbed ice temperature was $-21.1^{\circ} \mathrm{C}$, the temperature fell below the pressuredependent melting temperature $3 \mathrm{~h}$ after drilling. Within warmer ice, refreezing was slower: at $920 \mathrm{~m}$ depth in $\mathrm{BH} 19 \mathrm{c}$, the ice temperature was $-3^{\circ} \mathrm{C}$ and refreezing was complete after $5 \mathrm{~d}$.

\subsection{Pressure measurements}

Basal water pressures were recorded by vibrating wire piezometers (Geokon 4500SH) installed at the base of BH19c and BH19e and a current loop transducer (Omega Engineering Ltd. PXM319) installed at the base of $\mathrm{BH} 19 \mathrm{~g}$. Pressure records from the Geokon 4500SH were zeroed with atmospheric pressure at the surface, temperature compensated using a high-accuracy thermistor in contact with the piezometer body, and calibrated using the manufacturer's second-order polynomial to an accuracy of \pm 3 $\mathrm{kPa}$, equivalent to $\pm 0.3 \mathrm{~m}$ of hydraulic head. The pressure record 
from the PXM319 current loop transducer (accuracy $= \pm 35 \mathrm{kPa}$, equivalent to $\pm 3.6 \mathrm{~m}$ of head) was calibrated using the manufacturer's linear calibration and zeroed with atmospheric pressure at the surface. A pressure spike indicates that the ice surrounding the transducer installed in $\mathrm{BH} 19 \mathrm{~g}$ froze at $13.7 \mathrm{~h}$ post-breakthrough.

All pressure sensors were lowered until contact with the ice-bed interface was confirmed by the pressure ceasing to increase. The sensor was then raised slightly (piezometer offset: $0.05-0.4 \mathrm{~m}$; Table 1) to prevent the piezometer from being dragged through the substrate. The borehole water level below the surface (that is the length of the uppermost air-filled section of the borehole) at installation was measured with a well depth meter, and by reference to distance markers on the piezometer cable. The final installation depth was determined by adding this water level to the depth recorded by the piezometer. The ice thickness $\left(H_{\mathrm{i}}\right)$ was calculated by adding the piezometer offset to the final installation depth. Borehole positions were surveyed on 22 July 2019 using a Trimble R9s GNSS receiver with $8 \mathrm{~min}$ long observations postprocessed using the precise point positioning service provided by Natural Resources Canada (CSRS-PPP). Borehole surface elevation was converted to orthometric EGM96 geoid heights. To allow inter-comparison of pressure records from sensors installed at different depths below the surface, water pressure was expressed as hydraulic head $h$, which represents the theoretical orthometric height of the borehole water level,

$$
h=\frac{p_{\mathrm{w}}}{\rho_{\mathrm{w}} g}+z
$$

where $\rho_{\mathrm{w}}=999.8 \mathrm{~kg} \mathrm{~m}^{-3}$ is water density at $0^{\circ} \mathrm{C}, g=9.81 \mathrm{~m} \mathrm{~s}^{-2}$ is gravitational acceleration and $z$ is the orthometric height of the piezometer determined by subtracting the piezometer depth below the surface from the orthometric height of the borehole at the surface. Pressure was also expressed as the effective pressure $N=p_{\mathrm{i}}-p_{\mathrm{w}}$ and the overpressure $\left(p_{\mathrm{w}}-p_{\mathrm{i}}\right)$, the latter in respect of the excess pressure exerted at the base of water-filled boreholes due to the greater density of water than ice (Table 1). The ice-overburden pressure $p_{\mathrm{i}}$ was approximated for an inclined, parallel-sided slab of ice as

$$
p_{\mathrm{i}}=\rho_{\mathrm{i}} g H_{\mathrm{i}} \cos \alpha
$$

where $\rho_{\mathrm{i}}$ is the density of ice, $H_{\mathrm{i}}$ is the height of the overlying ice column, $\alpha=1.0^{\circ}$ is the mean surface and bed slope (see Section 2.1 ), and ice density was taken as $\rho_{\mathrm{i}}=910 \pm 10 \mathrm{~kg} \mathrm{~m}^{-3}$.

\subsection{Temperature measurements}

Temperature was measured using high-accuracy $\left( \pm 0.05^{\circ} \mathrm{C}\right)$ thermistors (Littelfuse: PR502J2) at $\sim 0,1,3,5$ and $10 \mathrm{~m}$ above the bed in $\mathrm{BH} 19 \mathrm{c}$ and $\mathrm{BH} 19 \mathrm{e}$ and also throughout the full ice column in BH19c using fibre-optic DTS (Law and others, 2021). Here we present temperature measurements recorded by the lowermost thermistor in $\mathrm{BH} 19 \mathrm{c}$, which was mounted with the Geokon $4500 \mathrm{SH}$ piezometer. We calculated the pressure-dependent melting temperature

$$
T_{\mathrm{m}}=T_{\mathrm{tr}}-\gamma\left(p_{\mathrm{i}}-p_{\mathrm{tr}}\right)
$$

where $\gamma=9.14 \times 10^{-8} \mathrm{~K} \mathrm{~Pa}^{-1}$ is the Clausius-Clapeyron gradient determined from the basal temperature gradient (Law and others, 2021 ), and $T_{\mathrm{tr}}=273.16 \mathrm{~K}$ and $p_{\mathrm{tr}}=611.73 \mathrm{~Pa}$ are the triple point temperature and pressure of water, respectively.

\subsection{GNSS measurements of ice motion}

Time series of horizontal and vertical ice motion were determined from dual frequency (L1 + L2) GNSS data recorded by a Trimble R7 receiver at $0.1 \mathrm{~Hz}$ and post-processed kinematically using Precise Point Positioning with Ambiguity Resolution (CSRS PPP-AR). The GNSS antenna was mounted on a $5 \mathrm{~m}$ long pole drilled $4 \mathrm{~m}$ into the ice surface at a location between the two clusters of boreholes (Fig. 1b). Rapid re-freezing of the hole ensured effective coupling of the antenna pole with the ice. Small gaps $(<5 \mathrm{~min})$ in the position record were interpolated linearly before a $6 \mathrm{~h}$ low pass Butterworth filter was applied. The filtered position record was differentiated to calculate velocity. The time series was then resampled to $10 \mathrm{~min}$ medians and a further $6 \mathrm{~h}$ moving average was applied to the velocity record. To prevent a shift in phase, phase-preserving filters and differentiation were used.

\section{Borehole response tests}

We analysed the response of borehole water pressure to the perturbations induced at breakthrough, during the continued pumping of water into the borehole while the drill stem and hose were raised to the surface, and also during the recovery phase after which borehole water pressure was in equilibrium with the pressure in the subglacial drainage system. These tests were conducted at different times since breakthrough, allowing us to investigate whether hydraulic transmissivity changed as water pressure returned to equilibrium. Rapid borehole refreezing precluded slug testing. Below we describe the borehole response test results alongside the methods.

For the majority of tests the monitoring borehole was the same as the injection borehole and these are referred to simply by the borehole name. To distinguish response tests where the injection and monitoring boreholes were different, we give the injection borehole in full followed by the monitoring borehole's letter code in brackets. A conceptual illustration of our borehole response tests is presented in Figure 2.

All data loggers, including that of the drill, were synchronised precisely with Global Positioning System Time (GPST) immediately prior to drilling. Water pressure data were logged by separate Campbell Scientific CR1000X data loggers for each cluster of boreholes. The sampling frequency was increased to $0.2 \mathrm{~Hz}$ prior to borehole breakthrough, necessitating temporary suspension of thermistor measurements. Hence, no measurements of basal water temperature were made when drilling was taking place.

As it is difficult to measure the background hydraulic head without disturbing the subglacial environment it is necessary to define a reference head $\left(h_{0}\right)$. The head in BH19e averaged from $36-60 \mathrm{~h}$ after $\mathrm{BH} 19 \mathrm{~g}$ breakthrough had recovered to within $0.1 \mathrm{~m}$ of the mean head over the $24 \mathrm{~h}$ period preceding $\mathrm{BH} 19 \mathrm{~g}$ breakthrough (Fig. 3b). On this basis, we define $h_{0}$ as the mean head from $36-60 \mathrm{~h}$ post-breakthrough for all tests. No corrections for background trends in hydraulic head were made but such trends are small relative to the perturbations induced (Fig. 3a).

\subsection{Breakthrough tests}

\subsubsection{Observations}

All three boreholes drilled to the bed in 2019 drained rapidly upon intersecting the basal interface. During breakthrough, water levels dropped to an initial level measured during pressure transducer installation of 78,73 and $80 \mathrm{~m}$ below the surface in $\mathrm{BH} 19 \mathrm{c}, \mathrm{BH} 19 \mathrm{e}$ and $\mathrm{BH} 19 \mathrm{~g}$ (Table 1). The frictional drag of water flowing past the hose during breakthrough events caused 


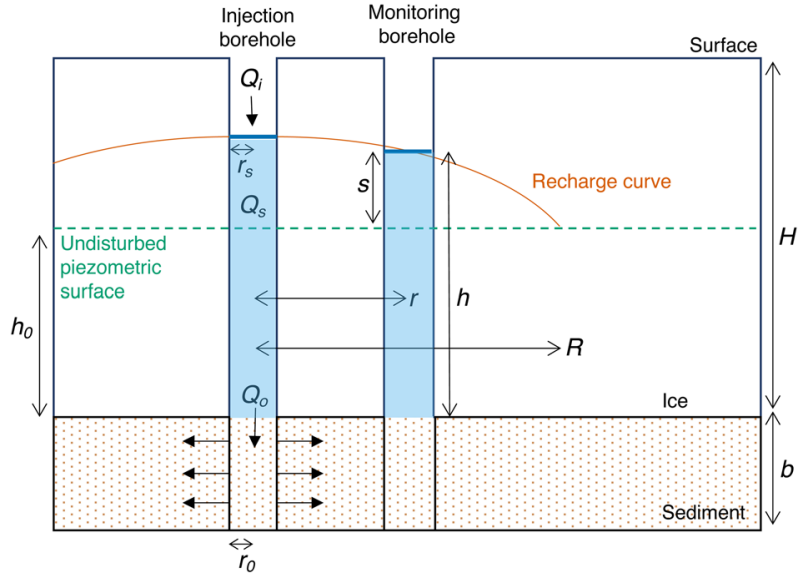

Fig. 2. Conceptual diagram and nomenclature for borehole drainage via radial Darcian flow through a subglacial sediment aquifer confined by an overlying ice aquiclude. Note that monitoring boreholes are likely to have refrozen at the time of the tests and $h$ is therefore the equivalent hydraulic head for the subglacial water pressure recorded.

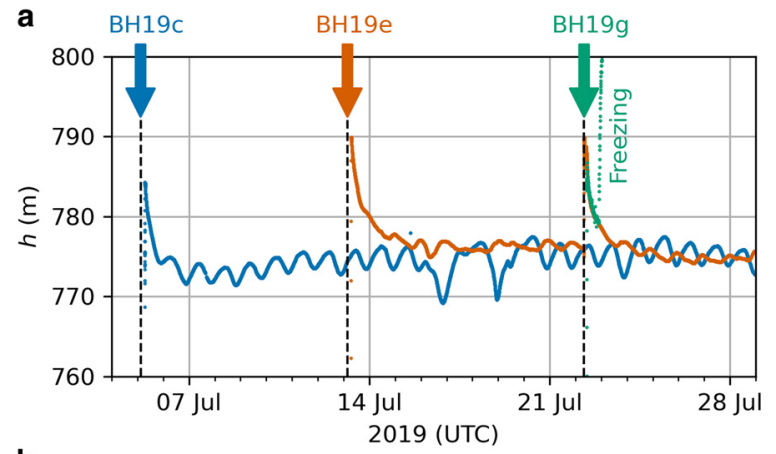

b

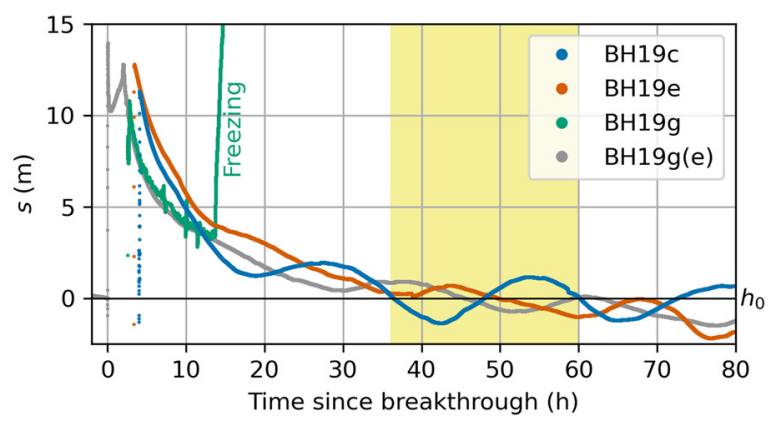

Fig. 3. (a) Time series of hydraulic head $(h)$. Borehole breakthrough times are marked with a vertical dashed line and arrow. (b) Time series of head above the reference head $\left(s=h-h_{0}\right)$ plotted against time since respective breakthrough for all breakthrough tests. The yellow shade marks the $24 \mathrm{~h}$ period selected to define $h_{0}$ (36$60 \mathrm{~h}$ post-breakthrough).

transient $\sim 2 \mathrm{kN}$ magnitude peak forces, as recorded on the drill tower (Figs 4, S1-S3). Following the peak, force on the drill tower became constant at $200 \mathrm{~s}$ post-breakthrough but at a higher level than recorded prior to breakthrough. The offset in the pre- and post-breakthrough force on the drill tower represents the difference between the weight of the hose in a water-filled and part-filled borehole.

As the drill stem was raised to the surface over $\sim 2 \mathrm{~h}$ water continued to be pumped into the borehole, supplying an additional $\sim 10 \mathrm{~m}^{3}$ of water (Table 1 ). The volume of water drained during the breakthrough events was determined from the initial water level and annular cross-sectional area of the borehole of near surface radius $\left(r_{\mathrm{s}}\right)$ containing the hose of external radius $\left(r_{\mathrm{d}}\right)$, yielding

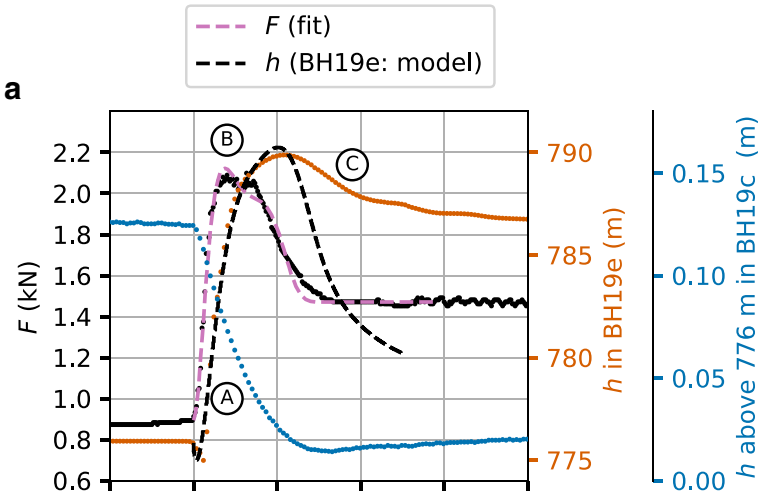

b

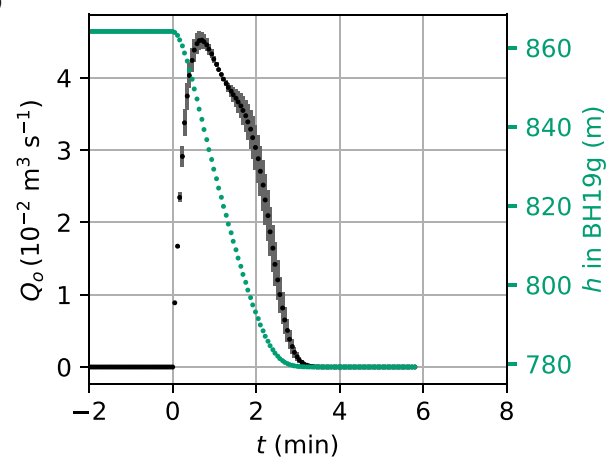

Fig. 4. (a) Force on the drill tower with best fit plotted against time since BH19g breakthrough, together with measured and modelled hydraulic head. (b) Volumetric flux into the subglacial drainage system $\left(Q_{0}\right)$ with error bars, and hydraulic head in $\mathrm{BH} 19 \mathrm{~g}$ determined by inverting the force on the drill tower. Labels $(a-c)$ are described in Section 4.1.

a mean volume for the three breakthrough events of $4.70 \mathrm{~m}^{3}$ (Table 1). Taking the duration of rapid drainage as the duration of the peak in force of $\sim 200 \mathrm{~s}$ gives a mean discharge for the three breakthrough events of $2.3 \times 10^{-2} \mathrm{~m}^{3} \mathrm{~s}^{-1}$ supplied from the borehole, with an additional flux supplied by the pumps $Q_{\mathrm{i}}=751 \mathrm{~min}^{-1}\left(1.25 \times 10^{-3} \mathrm{~m}^{3} \mathrm{~s}^{-1}\right)$ bringing the total discharge to $Q_{\mathrm{o}}=2.5 \times 10^{-2} \mathrm{~m}^{3} \mathrm{~s}^{-1}$, and the total volume over the $\sim 200 \mathrm{~s}$ duration to $4.95 \mathrm{~m}^{3}$. The Reynolds number for outflow from the base of the borehole can be approximated as flow through a uniform cylindrical pipe, with a radius equal to that at the borehole base, the mean of which was $r_{0}=0.10 \mathrm{~m}$ for the three boreholes (Table A1),

$$
R e=\frac{U_{\mathrm{w}} 2 r_{0} \rho_{\mathrm{w}}}{\eta_{\mathrm{w}}}=\frac{2 Q_{\mathrm{o}} \rho_{\mathrm{w}}}{\pi \eta_{\mathrm{w}} r_{0}}
$$

where $\eta_{\mathrm{w}}=0.0018 \mathrm{Pas}$ is the water viscosity at $0^{\circ} \mathrm{C}$. Water flow through the boreholes near the base was turbulent with a high $\operatorname{Re} \approx 87,500$ greatly exceeding the threshold for laminar flow of 2,000 (de Marsily, 1986).

\subsubsection{Determining the BH19g breakthrough flux}

To avoid sensor cables becoming tangled around the drill hose, pressure transducers were installed after the drill stem and hose had been recovered to the surface. Hence, no measurements of pressure were made within boreholes being drilled including during breakthrough. As the pressure response to $\mathrm{BH} 19 \mathrm{~g}$ breakthrough was captured by transducers already installed in $\mathrm{BH} 19 \mathrm{c}$ and $\mathrm{BH} 19 \mathrm{e}$ (Fig. 4) we now focus on the BH19g breakthrough.

We determined the time varying flux of water into the subglacial drainage system during the breakthrough of $\mathrm{BH} 19 \mathrm{~g}$ by inverting the recorded force on the drill tower from the hose, which is a combination of its weight, both in air and in water, and the 
frictional drag on the hose when the water drains through the borehole,

$$
\begin{aligned}
F(t)= & \pi r_{\mathrm{d}}^{2} \overline{\rho_{\mathrm{d}}} g\left(H_{\mathrm{w} 0}-H_{\mathrm{w}}\right)+\pi r_{\mathrm{d}}^{2} \Delta \bar{\rho} g H_{\mathrm{w}} \\
& +\frac{\pi r_{\mathrm{d}}}{4} f_{\mathrm{D}} \rho_{\mathrm{w}} U_{\mathrm{w}}^{2} H_{\mathrm{w}}+F_{\mathrm{s}},
\end{aligned}
$$

where $r_{\mathrm{d}}$ is the radius of the drill, $\overline{\rho_{\mathrm{d}}}$ is the mean density of the drill (including the water core), $\Delta \bar{\rho}=\overline{\rho_{\mathrm{d}}}-\rho_{\mathrm{w}}, f_{\mathrm{D}}$ is the coefficient of frictional drag exerted on the outside of the hose by the downrushing water in the borehole, $H_{\mathrm{w}}(t)$ is the height of water in the borehole, $F_{s}$ is the force exerted by the weight of the drill stem in water, and the bulk velocity of water in the borehole during the drainage event is $U_{\mathrm{w}}(t)=\mathrm{d} H_{\mathrm{w}} / \mathrm{d} t$.

The force on the drill hose is initially set by the water height, which for a borehole full to the surface is equal to the ice thickness, therefore $H_{\mathrm{w}}(t=0)=H_{\mathrm{w} 0}=H_{\mathrm{i}}=1039 \mathrm{~m}$ (Table 1). Since the initial force just before breakthrough $F_{0}=893 \mathrm{~N}$ the density difference between the hose and water is

$$
\Delta \bar{\rho}=\frac{F_{0}-F_{\mathrm{s}}}{\pi r_{\mathrm{d}}^{2} g H_{\mathrm{w} 0}}=96 \mathrm{~kg} \mathrm{~m}^{-3} .
$$

Taking $\rho_{\mathrm{w}}=999.8 \mathrm{~kg} \mathrm{~m}^{-3}$ gives a mean density of the hose filled with water $\overline{\rho_{\mathrm{d}}}=1096 \mathrm{~kg} \mathrm{~m}^{-3}$. Note that the composite density of the hose is

$$
\overline{\rho_{\mathrm{d}}}=\rho_{\mathrm{d}}-\left(\rho_{\mathrm{d}}-\rho_{\mathrm{w}}\right)\left(r_{\mathrm{d}} / \underline{r_{\mathrm{d}}}\right)^{2},
$$

where $\rho_{\mathrm{d}}$ is the density of the hose material, and $\underline{r}_{d}=9.7 \mathrm{~mm}$ is the internal bore radius of the hose. Using the calculated value of $\overline{\rho_{\mathrm{d}}}=1096 \mathrm{~kg} \mathrm{~m}^{-3}$ gives an estimate of the hose material density of $\rho_{\mathrm{d}}=1166 \mathrm{~kg} \mathrm{~m}^{-3}$, which is slightly larger than the nominal manufacturer's specification of $1149 \mathrm{~kg} \mathrm{~m}^{-3}$. This apparent extra density corresponds to an extra force measured on the drill tower prior to breakthrough of $65 \mathrm{~N}$, which we interpret as a drag of $0.0625 \mathrm{~N}$ per metre of hose from the pumped water flowing down the centre of the hose.

Neglecting minor residual oscillations, the force $F_{\infty}=F$ $(t \rightarrow \infty)$ on the drill tower after the initial rapid breakthrough was again approximately constant and is given by

$$
F_{\infty}=1470 \pm 10 \mathrm{~N}=\pi r_{\mathrm{d}}^{2} g\left[\overline{\rho_{\mathrm{d}}}\left(H_{\mathrm{w} 0}-H_{\mathrm{w} \infty}\right)+\Delta \bar{\rho} H_{\infty}\right]
$$

From this we can infer that the final height of the water level $H_{\mathrm{w} \infty}=954 \pm 1 \mathrm{~m}$. That is, during $\mathrm{BH} 19 \mathrm{~g}$ breakthrough the water in $\mathrm{BH} 19 \mathrm{~g}$ transiently drops $H_{\mathrm{w} 0}-H_{\mathrm{w} \infty} \approx 85 \mathrm{~m}$ below the surface.

Following $\mathrm{BH} 19 \mathrm{~g}$ breakthrough a portion of the water in the borehole is rapidly evacuated into the subglacial environment. We know that the water level in the borehole decreases monotonically from an initial height $H_{0}$ to a final height $H_{\infty}$ and so fit the transient response with a modified exponential solution of the form

$$
H_{\mathrm{w}}=H_{\mathrm{w} \infty}+\left(H_{\mathrm{w} 0}-H_{\mathrm{w} \infty}\right) e^{-y(t)},
$$

where

$$
y(t)=c_{1} t^{2}+c_{1} t^{3}+c_{1} t^{4}
$$

A fourth order polynomial was found to be the lowest order of polynomial to accurately represent the data. The flux of water from the borehole into the subglacial environment $\left(Q_{0}\right)$ can then be given by

$$
Q_{\mathrm{o}}(t)=\pi r_{\mathrm{d}}^{2} U_{\mathrm{w}}(t)+Q_{\mathrm{i}}=\pi r_{\mathrm{d}}^{2} \frac{\mathrm{d} H_{\mathrm{w}}}{\mathrm{d} t}+Q_{\mathrm{i}},
$$

where $Q_{\mathrm{i}}=1.25 \times 10^{-3} \mathrm{~m}^{3} \mathrm{~s}^{-1}$ is the input flux from the drill. The three constants in the polynomial $y(t), c_{i}$ where $i=1, \ldots, 3$, along with the drag coefficient $f_{\mathrm{D}}$ were estimated using non-linear regression (MATLAB: fitnlm). The resulting constants, with error estimation, are given in Table S2. From this fit $\left(R^{2}=\right.$ 0.996) of the force on the drill hose the height of water, and therefore hydraulic head, in $\mathrm{BH} 19 \mathrm{~g}$ can be calculated, together with the flux into the subglacial hydrological network (Fig. $4 \mathrm{~b}$ ). This reveals that the discharge peaked at $4.5 \pm 0.1 \times 10^{-2} \mathrm{~m}^{3} \mathrm{~s}^{-1}$ at $38 \mathrm{~s}$ after breakthrough.

\subsubsection{Modelling the pressure response to $\mathrm{BH} 19 \mathrm{~g}$ breakthrough}

Distinct pressure perturbations, here expressed as hydraulic head, occurred in $\mathrm{BH} 19 \mathrm{c}$ and $\mathrm{BH} 19 \mathrm{e}$ following the breakthrough of BH19g (Fig. 4a). In $\mathrm{BH} 19 \mathrm{e}$, located $4.1 \mathrm{~m}$ from $\mathrm{BH} 19 \mathrm{~g}$, head instantaneously decreased by $0.93 \mathrm{~m}$ over a $20 \pm 5 \mathrm{~s}$ period before rising rapidly and peaking at $14.0 \mathrm{~m}$ above its pre-breakthrough level $130 \pm 5 \mathrm{~s}$ post-breakthrough. Synchronously with the drop in head observed in $\mathrm{BH} 19 \mathrm{e}$, a $0.11 \mathrm{~m}$ drop in head began in BH19c.

To analyse these pressure perturbations further we modelled the propagation of water at the contact between elastic ice and poroelastic sediment during $\mathrm{BH} 19 \mathrm{~g}$ breakthrough following Hewitt and others (2018). The Maxwell time for the basal temperate ice at site R30 is $10-25 \mathrm{~min}$, and it is therefore reasonable to assume an elastic ice rheology for the short duration $(<4 \mathrm{~min})$ of breakthrough events (Appendix C). This model accounts for pressure diffusion, flexure of the ice and deformation of the sediment, and was originally developed to describe the subglacial response to a rapidly draining supraglacial lake. The original model, which is based on Darcy's law, allowed for the formation of a subglacial cavity as well as seepage through the sediment or established subglacial networks. However, for simplicity, here we do not include cavity formation and instead assume a single effective hydraulic transmissivity for subglacial water transport; and that the fluid is incompressible. The model allows the poroelastic sediment layer to deform in response to fluid flow and pressure gradients, which allows the overlying ice to flex and bend slightly as reflected in the small $(0.93 \mathrm{~m})$ transient head decrease preceding the large $(14.0 \mathrm{~m})$ head increase recorded in $\mathrm{BH} 19 \mathrm{e}$ following BH19g breakthrough (Fig. 4a). With these features included, the model shows how an injected fluid diffuses through the subglacial environment and how this drives a propagating flexural wave in the overlying ice.

The linearised form of the model reduces to an evolution equation for the subglacial water pressure, which for consistency is here expressed as hydraulic head $h$

$$
\rho g \frac{\partial h}{\partial t}=A_{1} \nabla^{2} h+A_{2} \nabla^{6} h
$$

Here $A_{1}=T M / b$ and $A_{2}=T B$, in terms of transmissivity $T$, till stiffness (p-wave modulus) $M$, bending modulus of the ice $B$, and sediment thickness $b$. Here $b$ is a fitting parameter, unconstrained by measurements of the actual sediment thickness, that represents the thickness of sediment affected by pressure diffusion. Assuming radial flow,

$$
\nabla^{2}=\frac{1}{r} \frac{\partial}{\partial r} r \frac{\partial}{\partial r},
$$


the associated flux of water $q$ at radius $r$ is

$$
q(r)=-2 \pi r T \frac{\partial h}{\partial r}
$$

and $q(r)=Q_{o}(t)$ is the injection flux into the subglacial environment.

This problem can be solved numerically for any injection flux $Q_{0}(t)$. By entering the time-varying injection flux for $\mathrm{BH} 19 \mathrm{~g}$ breakthrough (Section 3.1.2) into Eqn (14), we predicted the response of hydraulic head at $\mathrm{BH} 19 \mathrm{e}(4.1 \mathrm{~m}$ from the injection point of $\mathrm{BH} 19 \mathrm{~g})$. An automated non-linear optimisation procedure (MATLAB: fitnlm) was used to determine the best-fit model parameters, yielding $B=2.75 \times 10^{9} \mathrm{~Pa} \mathrm{~m}^{3}, M / b=1 \times 10^{4} \mathrm{~Pa} \mathrm{~m}^{-1}$, and $T=1.46 \times 10^{-4} \mathrm{~m}^{2} \mathrm{~s}^{-1}$. The prediction initially follows the data closely and it captures the initial decrease in $\mathrm{BH} 19 \mathrm{e}$ hydraulic head as the flexural wave passes through (Fig. 4a). However, the model does not capture the subsequent development of the pressure recorded in $\mathrm{BH} 19 \mathrm{e}$; instead it predicts that the pressure drops off too rapidly after the first two minutes. We discuss this discrepancy further in Section 4.1.

\subsection{Pumping tests}

\subsubsection{Observations}

Following each breakthrough event, the hose was raised back to the surface over $\sim 2 \mathrm{~h}$ (Table 1; Figs S1-S3), with the continued supply of water into the borehole functioning as a pumping test. We captured the pressure response at the base of $\mathrm{BH} 19 \mathrm{e}$ to such a pumping test following the breakthrough of $\mathrm{BH} 19 \mathrm{~g}$ (Fig. 5). Although water was pumped down the hose while it was raised to the surface for all boreholes that reached the bed, no other pumping tests were useful as they occurred prior to the installation of pressure sensors. During the BH19g(e) pumping test the water pressure was measured in $\mathrm{BH} 19 \mathrm{e}, 4.1 \mathrm{~m}$ distant (Fig. 5).

Starting $28 \mathrm{~min}$ after the breakthrough of $\mathrm{BH} 19 \mathrm{~g}$ the head in BH19e increased at a steady rate of $1.24 \mathrm{~m} \mathrm{~h}^{-1}$ (Fig. 5). This period of steady increase was interrupted by the temporary shutdown of the water supply when pressure-heater units were refuelled, with the linear increase in head resuming at the slightly higher rate of $1.36 \mathrm{~m} \mathrm{~h}^{-1}$. The rate of change of hydraulic head increased again to $7.40 \mathrm{~m} \mathrm{~h}^{-1}$ when the drill stem and hose rose above the borehole water level, indicating that, while the stem was below the water line, part of the water pumped into the borehole was replacing the reducing volume displaced by the hose as it was raised to the surface. We refer to these three periods of linearly increasing head as PT1, PT2 and PT3, respectively.

Discharge from the base of $\mathrm{BH} 19 \mathrm{~g}\left(Q_{o}\right)$ was calculated by correcting the input flux $Q_{\mathrm{i}}\left(1.25 \times 10^{-3} \mathrm{~m}^{3} \mathrm{~s}^{-1}\right)$ for storage within BH19g $\left(Q_{s}\right)$, and for the flux offsetting the decreasing water displacement caused by the hose as it was raised to the surface $\left(Q_{d}\right)$

$$
Q_{\mathrm{o}}=Q_{\mathrm{i}}-Q_{\mathrm{d}}-Q_{\mathrm{s}} .
$$

The pumping test was undertaken $9 \mathrm{~d}$ after the breakthrough of $\mathrm{BH} 19 \mathrm{e}$. Hence, we assume that storage within $\mathrm{BH} 19 \mathrm{e}$ was negligible due to rapid borehole refreezing within cold ice that was present above a $70 \mathrm{~m}$ thick basal temperate layer (Law and others, 2021). We also consider storage within temperate ice to be negligible within the time span of our experiments due to its low permeability (e.g., $10^{-12}-10^{-8} \mathrm{~m}^{2}$; Haseloff and others, 2019). $Q_{\mathrm{d}}$ was calculated as

$$
Q_{\mathrm{d}}=\pi r_{\mathrm{d}}^{2} \bar{U}_{\mathrm{d}}
$$

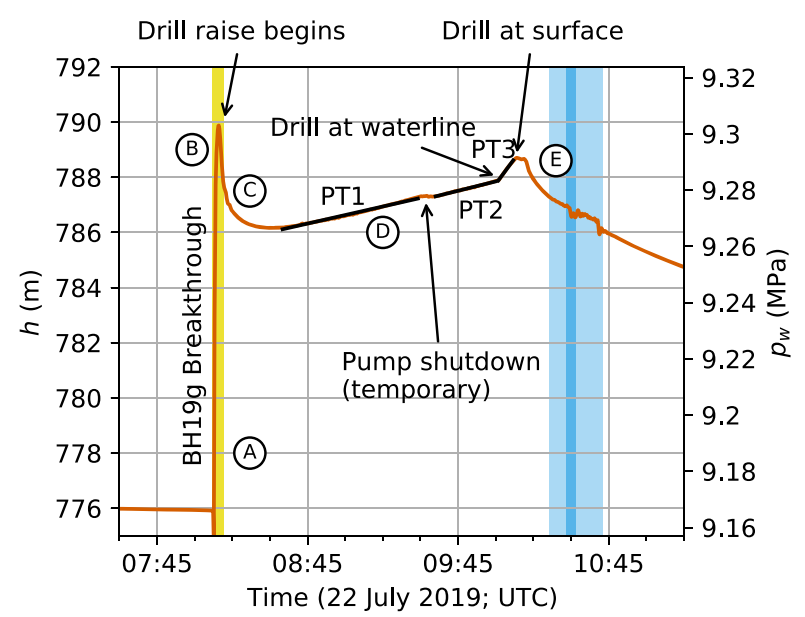

Fig. 5. Time series of $\mathrm{BH} 19 \mathrm{e}$ hydraulic head (red line) capturing the response to $\mathrm{BH} 19 \mathrm{~g}$ breakthrough and the injection of water as the hose was raised to the surface. Post-breakthrough the drill stem was kept stationary at the bed for 4 min $39 \mathrm{~s}$ (yellow shading). Linear fits during the three pumping test periods are shown with black lines. The light blue shade marks the period during which a piezometer was lowered into $\mathrm{BH} 19 \mathrm{~g}$, and the dark blue shade marks the time the piezometer was temporarily snagged (see Section 4.1 for details). Labels (a-e) are also described in Section 4.1.

where $r_{\mathrm{d}}=0.015 \mathrm{~m}$ is the hose radius and $\bar{U}_{\mathrm{d}}$ is the mean drill speed. For PT3, $Q_{d}=0$ as the drill stem and hose were above the borehole water level. $Q_{s}$ is the flux lost to storage in the injection borehole calculated from the rate of change in head $\mathrm{d} h / \mathrm{d} t$ and the cross-sectional area of the borehole, which for PT1 and PT2 is annular as the hose was below the borehole water level

$$
Q_{\mathrm{s}}=\left(\pi r_{\mathrm{s}}^{2}-\pi r_{\mathrm{d}}^{2}\right) \frac{\mathrm{d} h}{\mathrm{~d} t},
$$

where $r_{\mathrm{s}}=0.14 \mathrm{~m}$ is the radius of $\mathrm{BH} 19 \mathrm{~g}$ at the surface (see Appendix B). For PT3

$$
Q_{\mathrm{s}}=\pi r_{\mathrm{s}}^{2} \frac{\mathrm{d} h}{\mathrm{~d} t}
$$

As the measurement of hydraulic head in $\mathrm{BH} 19 \mathrm{~g}$ did not start until after the pumping test, we assume that the rate of change of hydraulic head was the same in BH19g and BH19e.

These calculations reveal that during the pumping test the vast majority (90\%) of water pumped into the borehole was discharged from the base (Table 2). Furthermore, this discharge from the borehole base $\left(Q_{0}\right)$ was remarkably steady, averaging $1.12 \times$ $10^{-3} \mathrm{~m}^{3} \mathrm{~s}^{-1}$ with a standard deviation of $1.1 \times 10^{-6} \mathrm{~m}^{3} \mathrm{~s}^{-1}$. It follows that the bulk velocity of the water $\left(\bar{U}_{\mathrm{w}}=Q_{\mathrm{o}} / \pi r_{0}^{2}\right)$ through the borehole near the base during all periods was also steady, averaging $3.2 \times 10^{-2} \mathrm{~m} \mathrm{~s}^{-1}$ with a standard deviation of $3.1 \times$ $10^{-5} \mathrm{~m} \mathrm{~s}^{-1}$.

To test whether the outflow of borehole water during the pumping test was laminar or turbulent we calculated the Reynolds number $(R e)$ using Eqn (4). During all periods, $R e \approx$ 3750 , indicating that flow of water in the bottom of the borehole was turbulent during the pumping tests. If, however, we assume that water leaves the borehole through a gap of width $\delta$ the Reynolds number for flow through this gap is

$$
R e=\frac{Q_{\mathrm{o}} D_{\mathrm{h}} \rho_{\mathrm{w}}}{2 \phi \pi r \delta \eta_{\mathrm{w}}}
$$

where $D_{\mathrm{h}}$ is the hydraulic diameter of the water film, $r$ is the distance from the borehole, and $\phi$ is the areal fraction of the bed occupied by the gap (de Marsily, 1986; Iken and others, 1996). 
Table 2. Statistics for the $\mathrm{BH} 19 \mathrm{~g}(\mathrm{e})$ pumping test. $V_{\mathrm{o}}$ is the volume of water discharged from the borehole base during the period. All other symbols are defined in the text.

\begin{tabular}{llll}
\hline Period & \multicolumn{1}{c}{ PT1 } & \multicolumn{1}{c}{ PT2 } & \multicolumn{1}{c}{ PT3 } \\
\hline Time since breakthrough (h) & 0.9 & 1.7 & 1.9 \\
Duration (min) & 54 & 24 & 6 \\
$\mathrm{~s}(\mathrm{~m})$ & 11.2 & 12.1 & 12.8 \\
$\mathrm{~d} h / \mathrm{d} t\left(\mathrm{~m} \mathrm{~h}^{-1}\right)$ & 1.24 & 1.36 & 7.40 \\
$\bar{U}_{\mathrm{d}}\left(\mathrm{m} \mathrm{min} \mathrm{min}^{-1}\right.$ & 8.80 & 8.82 & 8.75 \\
$Q_{\mathrm{i}}\left(10^{-4} \mathrm{~m}^{3} \mathrm{~s}^{-1}\right)$ & 12.5 & 12.5 & 12.5 \\
$Q_{\mathrm{d}}\left(10^{-4} \mathrm{~m}^{3} \mathrm{~s}^{-1}\right)$ & 1.04 & 1.04 & 0 \\
$Q_{\mathrm{s}}\left(10^{-4} \mathrm{~m}^{3} \mathrm{~s}^{-1}\right)$ & 0.210 & 0.231 & 1.27 \\
$Q_{\mathrm{o}}\left(10^{-4} \mathrm{~m}^{3} \mathrm{~s}^{-1}\right)$ & 11.3 & 11.2 & 11.2 \\
$Q_{\mathrm{o}}\left(\%\right.$ of $\left.\mathrm{Q}_{\mathrm{i}}\right)$ & 90.0 & 89.8 & 89.8 \\
$V_{\mathrm{o}}\left(\mathrm{m}^{3}\right)$ & 3.65 & 1.62 & 0.41 \\
$T_{\mathrm{s}}^{*}\left(10^{-5} \mathrm{~m}^{2} \mathrm{~s}^{-1}\right)$ & $1.51-4.75$ & $1.39-4.37$ & $1.31-4.13$ \\
$T^{\dagger}\left(10^{-5} \mathrm{~m}^{2} \mathrm{~s}^{-1}\right)$ & 7.96 & 3.93 & 0.62 \\
\hline
\end{tabular}

Calculated using the Thiem (1906) method (Eqn (21)).

${ }^{\dagger}$ Calculated using the analytical solution to the simplified Hewitt and others (2018) model (Eqn (23b)).

For thin films with a large lateral extent $D_{\mathrm{h}}$ can be approximated as $2 \delta$ (de Marsily, 1986) and the equation can be simplified to

$$
R e=\frac{Q_{\mathrm{o}} \rho_{\mathrm{w}}}{\phi \pi r \eta_{\mathrm{w}}} .
$$

Using Eqn (20) and following the approach of Lüthi (1999), the transition from turbulent to laminar flow occurs at a distance of $\sim 1 \mathrm{~m}$ from the borehole base for even the low value of $\phi=$ 0.1 . Hence, water flow beyond this point can be treated as laminar allowing the application of standard hydrogeological techniques.

\subsubsection{Hydraulic transmissivity according to the Thiem method}

The hydraulic transmissivity $\left(T_{\mathrm{s}}\right)$ of a subglacial sediment layer can be calculated by applying the Thiem (1906) method to the pumping test data. The Thiem method assumes that a steady state has been reached within a vertically-confined, homogeneous, isotropic and incompressible aquifer with Darcian flow. In these limits the hydraulic transmissivity

$$
T_{\mathrm{s}}=\frac{Q_{\mathrm{o}}}{2 \pi s} \ln \frac{R}{r}
$$

where $r=4.1 \mathrm{~m}$ is the horizontal distance between the injection borehole (BH19g) and the monitoring borehole (BH19e), and $s=h-h_{0}$, is the mean hydraulic head $(h)$ during the pumping test above the reference head $\left(h_{0}\right)$. The radius of influence $(R)$ is the distance to the theoretical point at which the hydraulic head remains unchanged at the equilibrium level (i.e. at radial distance $R, h=h_{0} ; s=0$; Fig. 2). (Note that the subscript in $T_{\mathrm{s}}$ indicates that the method used assumes Darcian flow through sediment rather than through a gap at the ice-sediment interface, later denoted $T_{\mathrm{g}}$, or some combination of the two, for which we use $T$ to represent the effective transmissivity.) The strong response of hydraulic head in $\mathrm{BH} 19 \mathrm{e}$ to breakthrough in $\mathrm{BH} 19 \mathrm{~g}$ and the close agreement between head in these boreholes during the recovery phase (Fig. 3) indicates that the radius of influence is greater than the distance between $\mathrm{BH} 19 \mathrm{e}$ and $\mathrm{BH} 19 \mathrm{~g}$, which is $4.1 \mathrm{~m}$ at the surface. On the other hand, assuming a homogeneous, isotropic aquifer, the lack of a positive pressure peak in $\mathrm{BH} 19 \mathrm{c}$ suggests the radius of influence is $<70 \mathrm{~m}$. Using the Thiem (1906) Eqn 21, and reasonable $R$ values of 10 and $70 \mathrm{~m}$ gives hydraulic transmissivity from $(1.31-4.75) \times 10^{-5} \mathrm{~m}^{2} \mathrm{~s}^{-1}$ (Table 2).

Although the Thiem (1906) method is well established, it has limitations. The first is that the radius of influence $R$ is difficult to interpret physically. The second is the requirement that a steady state has been reached. A third limitation in our application is that to calculate the flux of water leaving the base of the injection borehole $(\mathrm{BH} 19 \mathrm{~g})$ we assume that the rate of change in hydraulic head is the same in BH19g as that recorded in BH19e.

\subsubsection{Hydraulic transmissivity according to the Hewitt model}

An alternative method to calculate the transmissivity from the pumping test data is through the application of an analytical solution to the simplified Hewitt and others (2018) model. During the pumping test $Q_{o}$ is steady, thereby permitting an asymptotic solution of Eqn (12) that, based on the monitoring borehole at radius $r$ being sufficiently near to the injection borehole, gives

$$
h(r) \rightarrow-\frac{Q_{\mathrm{o}}}{2 \pi T} \ln \left(r \sqrt{\frac{\rho g}{A_{1} t}}\right) .
$$

Hence, the predicted rate of change in hydraulic head at the nearby monitoring borehole is:

$$
\frac{\partial h}{\partial t} \rightarrow \frac{Q_{\mathrm{o}}}{4 \pi T t} \quad T=\frac{Q_{\mathrm{o}}}{4 \pi t}\left(\frac{\partial h}{\partial t}\right)^{-1} .
$$

This expression is independent of parameters $B, M$ and $b$ and is sensitive only to the transmissivity. In principle this provides an alternative means of predicting $T$ from the measured rate of change in hydraulic head during the pumping test, which avoids the limitations of the Thiem (1906) method outlined in Section 3.2.2. This method (Eqn (23b)) gives estimates of $T$ decreasing from $7.96 \times 10^{-5} \mathrm{~m}^{2} \mathrm{~s}^{-1}$ during PT1, to $3.93 \times 10^{-5} \mathrm{~m}^{2} \mathrm{~s}^{-1}$ during $\mathrm{PT} 2$, to $0.62 \times 10^{-5} \mathrm{~m}^{2} \mathrm{~s}^{-1}$ during PT3 (Table 2).

\subsection{Recovery tests}

\subsubsection{Observations}

After water input to the borehole ceased, the borehole water pressure recovered to the reference head $\left(h_{0}\right)$ over $\sim 36-50 \mathrm{~h}$ (Fig. $3 \mathrm{~b}$; Table 1). The range in recovery times can be explained by the variable timing and magnitude of the diurnal cycle in subglacial water pressure (Fig. 3). The observed recovery curves were similar (Fig. 3b) suggesting spatially uniform subglacial hydrological conditions between boreholes. We analysed the early phase of the recovery by fitting an exponential decay curve (Weertman, 1970, 1972; Engelhardt and Kamb, 1997) and the late phase using the Cooper and Jacob (1946) recovery test method. This provides two further estimates of hydraulic transmissivity: the first at $4-5 \mathrm{~h}$ post-breakthrough (early-phase), and the second at $14-27 \mathrm{~h}$ post-breakthrough (late-phase).

\subsubsection{Exponential decay curve}

The early phase of the recovery curve can be approximated as an exponential decay using the water-film model of Weertman (1970, 1972):

$$
s(t)=s_{0} \exp \frac{-t}{D}
$$

where $s_{0}$ is the initial recharge at the time the pumps stopped, $t$ is the time since the pumps stopped, and $D$ is a time constant determined by log-linear fitting (Figs $6 \mathrm{a}-\mathrm{c}$ ). The water-film model, which is referred to as the gap-conduit model in Engelhardt and Kamb (1997), is based on the Hagen-Poiseuille equation and assumes laminar flow through a constant-width gap at the interface between the ice and a level, impermeable bed. 

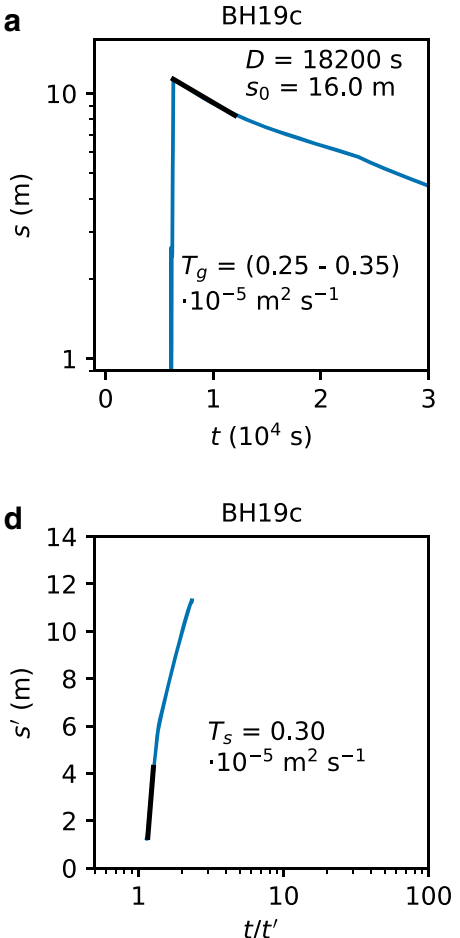

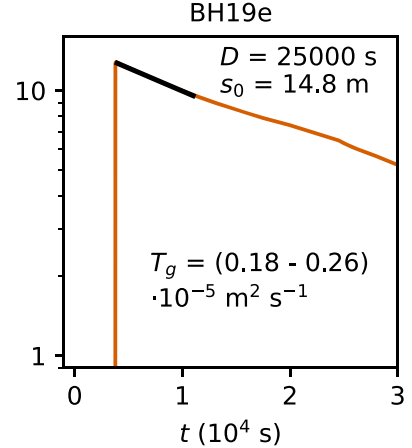

e

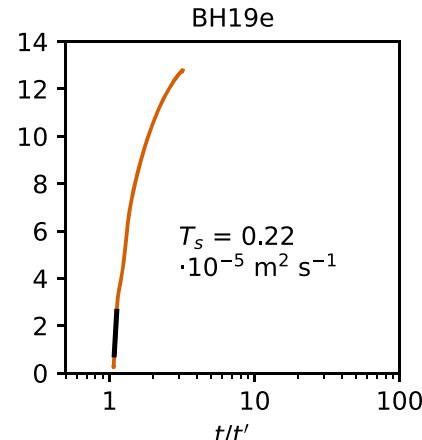

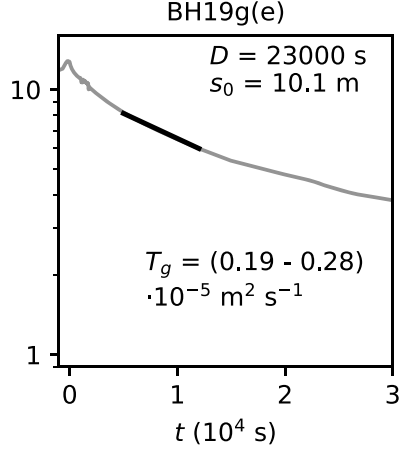

f

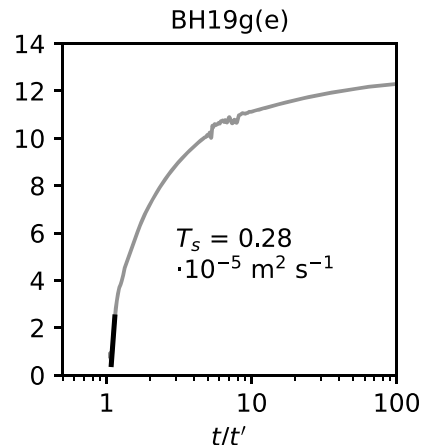

Fig. 6. Recovery tests including (a-c) exponential fits (black) applied to the early stage of recovery curves plotted as hydraulic head above background (s) on the logarithmic $y$-axis against time $(t)$; and (d-e) Cooper and Jacob (1946) recovery test linear-log fitting (black) applied to the late stage of the recovery curves plotted as residual drawdown $\left(s^{\prime}\right)$ against the logarithm of the time ratio $\left(t / t^{\prime}\right)$.

In the recovery curves of tests $\mathrm{BH} 19 \mathrm{c}$ and $\mathrm{BH} 19 \mathrm{e}$ the first part of the curve is missing due to the time taken to lower the pressure transducer to the bed after the drill stem was raised to the surface (Fig. 3a). Hence, $s_{0}$ was also treated as an unknown. In the BH19g (e) test the monitoring borehole was different from the injection borehole and the first part of the recovery curve was recorded. The initial $\mathrm{BH} 19 \mathrm{~g}(\mathrm{e})$ recovery curve was not, however, exponential and linear-log fitting was delayed for 5,000 s (83 min; Fig. 6c). After this delay the trend for $\mathrm{BH} 19 \mathrm{~g}(\mathrm{e})$ was quasi-exponential, in common with the other tests, and $s_{0}$ was again treated as an unknown for this test (Figs 6a-c). Hence, measured $s_{0}$ for BH19g(e) is 12.7 $\mathrm{m}$ and that calculated by fitting Eqn (24) is $10.1 \mathrm{~m}$. The resulting time constant $D$ was 18,200 s for $\mathrm{BH} 19 \mathrm{c}, 25,000$ s for $\mathrm{BH} 19 \mathrm{e}$ and $23,000 \mathrm{~s}$ for BH19g(e). Rearranging Eqn (9) of Engelhardt and Kamb (1997) allows the gap width $\delta$ to be calculated from the time constant as

$$
\delta=\left(\frac{6 \eta_{\mathrm{w}} r_{\mathrm{s}}^{2}}{D \rho_{\mathrm{w}} g \phi} \ln \frac{R}{r_{0}}\right)^{1 / 3}
$$

Furthermore, if we make the reasonable assumption of laminar flow at distances $>1 \mathrm{~m}$ from the borehole (Section 3.2), the transmissivity $\left(T_{\mathrm{g}}\right)$ of a continuous porous medium equivalent to a gap of width $\delta$ is given by de Marsily (1986) as

$$
T_{\mathrm{g}}=\delta^{3} \frac{\phi g \rho_{\mathrm{w}}}{12 \eta_{\mathrm{w}}}
$$

Combining Eqns (25) and (26) (see Appendix D) allows $T_{\mathrm{g}}$ to be calculated directly from the time constant $(D)$

$$
T_{\mathrm{g}}=\frac{r_{\mathrm{s}}^{2}}{2 D} \ln \frac{R}{r_{0}}
$$

For each test, two values of transmissivity were calculated, bracketing the radius of influence $R$ to $10-70 \mathrm{~m}$.
The results show that hydraulic transmissivity was an order of magnitude lower during the early recovery phase than during the pumping test, with hydraulic transmissivity spanning the range $(1.8-3.5) \times 10^{-6} \mathrm{~m} \mathrm{~s}^{-1}$ equivalent to gap widths of $0.16-0.20$ $\mathrm{mm}$ for gaps covering the whole of the glacier bed ( $\phi=1$; Table 3$)$.

\subsubsection{Cooper and Jacob recovery tests}

Hydraulic transmissivity can also be derived from the later stages of the recovery curve using the Cooper and Jacob (1946) recovery test method, providing information about the nature of the subglacial hydrological system as it returns to its original state. This method is based on the observation that, after a certain period of time, drawdown (or in our case drawup) within an aquifer at a given distance from a borehole decreases approximately in proportion to the logarithm of time since the discharge (or in our case recharge) began. The method assumes a non-leaky, vertically-confined aquifer of infinite lateral extent. Although the Theis (1935) method on which the Cooper and Jacob (1946) method is based requires a constant pumping rate, the method can be applied to a recovery test (i.e. after the pumps have ceased) using the principle of superposition of drawdown (e.g., de Marsily, 1986; Hiscock and Bense, 2014). Under this principle, pumping is assumed to continue uninterrupted while a hypothetical drawdown well is superimposed on the monitoring well from the time pumping stopped to exactly counteract the recharge from the pump. The residual drawup $s^{\prime}$ is

$$
s^{\prime}=h-h_{0}=\frac{Q}{4 \pi T}\left[W(u)-W\left(u^{\prime}\right)\right]
$$

where $h, h_{0}, Q$ and $T$ are as previously defined, and $W(u)$ and $W\left(u^{\prime}\right)$ are well functions for the real and hypothetical boreholes 
Table 3. Results from the gap-conduit model (exponential fit). Gap width and the apparent hydraulic transmissivity were calculated for two values of the radius of influence $(R=10$ and $70 \mathrm{~m})$. Gap widths were additionally calculated for two areal fractions of the bed covered by the gap $(\phi=0.1$ and 1.0). The apparent gap transmissivity is independent of $\phi$ because gap crosssectional area is a product of $\delta$ and $\phi$.

\begin{tabular}{|c|c|c|c|c|c|}
\hline \multirow[b]{2}{*}{ Test } & \multirow{2}{*}{$\begin{array}{c}S_{0} \\
(\mathrm{~m})\end{array}$} & \multirow{2}{*}{$\begin{array}{c}D \\
(\mathrm{~s})\end{array}$} & \multicolumn{2}{|c|}{$\delta(\mathrm{mm})$} & \multirow{2}{*}{$\begin{array}{c}T_{\mathrm{g}} \\
\left(10^{-5} \mathrm{~m} \mathrm{~s}^{-1}\right.\end{array}$} \\
\hline & & & $\phi=1$ & $\phi=0.1$ & \\
\hline $\mathrm{BH} 19 \mathrm{c}$ & 16 & 18,200 & $0.18-0.20$ & $0.38-0.43$ & $0.25-0.35$ \\
\hline $\mathrm{BH} 19 \mathrm{e}$ & 14.8 & 25,000 & $0.16-0.18$ & $0.34-0.38$ & $0.18-0.26$ \\
\hline $\mathrm{BH} 19 \mathrm{~g}(\mathrm{e})$ & 10.1 & 23,000 & $0.16-0.18$ & $0.35-0.39$ & $0.19-0.28$ \\
\hline
\end{tabular}

where

$$
u=\frac{r^{2} S}{4 T t}, \quad u^{\prime}=\frac{r^{2} S}{4 T t^{\prime}}
$$

and $S$ is the storage coefficient, which cannot be determined using this method. In the previous two equations, $t$ is time since the start of pumping, which for our tests is at breakthrough, and $t^{\prime}$ is the time since the pumps stopped. As per the standard Cooper and Jacob (1946) method for pumping tests, for small values of $u^{\prime}$ and large values of $t^{\prime}$, the well functions can be approximated so that residual drawup can be estimated from the simplified equation

$$
s^{\prime}=\frac{2.303 Q}{4 \pi T} \log _{10} \frac{t}{t^{\prime}} .
$$

Hence, linear-log fitting allows hydraulic transmissivity $\left(T_{\mathrm{s}}\right)$ to be calculated,

$$
T_{\mathrm{s}}=\frac{2.303 Q}{4 \pi \Delta s^{\prime}}
$$

where $\Delta s^{\prime}$ is the rate of change of residual drawup with respect to the logarithmic time ratio. The Cooper and Jacob (1946) recovery test method described above has the advantage that the rate of recharge can be assumed to be constant, in contrast to that during an actual pumping test, which may vary (Hiscock and Bense, 2014).

During the recovery phase, the sampling interval was increased from 5 to $300 \mathrm{~s}$. Prior to application of the Cooper and Jacob (1946) recovery test method, the data were resampled to a constant $5 \mathrm{~s}$ interval and interpolated linearly. The data presented in Figures $6 \mathrm{~d}-\mathrm{f}$ extend from the time of pressure transducer installation at the bed (or in the case of BH19g the earlier time at which the pumps were stopped), to when diurnal pressure variations began. Fitting was applied to the later stages of the recovery curve where the trend in recharge versus the logarithmic time ratio was linear, as is required for this method to be appropriate. Accordingly, hydraulic transmissivity was calculated to be $3.0 \times$ $10^{-6} \mathrm{~m}^{2} \mathrm{~s}^{-1}, 2.2 \times 10^{-6} \mathrm{~m}^{2} \mathrm{~s}^{-1}$ and $2.8 \times 10^{-6} \mathrm{~m}^{2} \mathrm{~s}^{-1}$ for BH19c, $\mathrm{BH} 19 \mathrm{e}$ and $\mathrm{BH} 19 \mathrm{~g}$ respectively.

\section{Discussion}

\subsection{Hydraulic ice-sediment separation}

The average drop in borehole water level during breakthrough indicates that the subglacial environment accommodated 4.70 $\mathrm{m}^{3}$ of water within $200 \mathrm{~s}$. For all three boreholes that reached the bed, the delayed recovery to background levels over $36-50$ $\mathrm{h}$ suggests that this breakthrough water and an additional $\sim 10$ $\mathrm{m}^{3}$ of water injected during the raise, could not be efficiently drained away from the immediate vicinity of the borehole's base. For example, recovery to the reference head took $45 \mathrm{~h}$ following the input of $13.6 \mathrm{~m}^{3}$ of water injected into $\mathrm{BH} 19 \mathrm{~g}$ at breakthrough and during the drill stem raise (Table 1; Fig. 3b) yielding a mean discharge of $8.4 \times 10^{-5} \mathrm{~m}^{3} \mathrm{~s}^{-1}$. If the boreholes had intercepted a conduit with the capacity to drain the water away efficiently then the mean discharge rate would have been higher and the recovery time would have been shorter. Hence, it follows that at least some of this water must have been temporarily stored locally. We hypothesise that water was predominantly stored within a gap opened at the ice-sediment interface facilitated by the overpressure $(913 \pm 101 \mathrm{kPa}$; Table 1$)$ exerted at the base of water-filled boreholes due to the greater density of water than ice. In the following analysis we constrain the geometry of this gap and investigate how the gap width changed through time.

An approximate calculation of the plausible range in gap width can be made for the $\mathrm{BH} 19 \mathrm{~g}$ breakthrough by assuming a uniform cylindrical subglacial water sheet with a radius ranging from $10-$ $70 \mathrm{~m}$ (that is just greater than the distance to $\mathrm{BH} 19 \mathrm{e}$ where a positive peak in pressure was observed and just less than the distance to $\mathrm{BH} 19 \mathrm{c}$ where there was no positive peak in pressure). Under these assumptions, a gap width of $0.3-16.5 \mathrm{~mm}$ could accommodate the $5.17 \mathrm{~m}^{3}$ of water injected in $200 \mathrm{~s}$ after BH19g breakthrough. This range is consistent with a lack of discernible ice surface uplift in data collected by a GNSS receiver at R30, confirming that surface uplift was below the precision of the GNSS data of $\pm 50 \mathrm{~mm}$ (Fig. S4). Assuming a straight-sided cylinder with a volume equal to that injected during $\mathrm{BH} 19 \mathrm{~g}$ of $5.17 \mathrm{~m}^{3}$ the upper bound on the surface uplift of $50 \mathrm{~mm}$ provides a lower bound on the radius of the uplift of $\sim 5.7 \mathrm{~m}$.

Further estimates of gap widths can be determined from the hydraulic transmissivity measurements. If we assume laminar flow, which is reasonable at distances $>1 \mathrm{~m}$ from the borehole (see Section 3.2), the gap width ( $\delta$ ), equivalent to a continuous porous medium with an effective hydraulic transmissivity $\left(T_{\mathrm{g}}\right)$, is given by rearranging Eqn (26)

$$
\delta=\left(\frac{12 T_{\mathrm{g}} \eta_{\mathrm{w}}}{\phi \rho_{\mathrm{w}} g}\right)^{1 / 3} .
$$

Assuming the gap is uniformly distributed across the bed $(\phi=1)$ these estimates show a decrease from $0.69 \mathrm{~mm}$ during breakthrough to a mean of $0.18 \mathrm{~mm}$ during the late recovery phase (Table 4; Fig. 7). A comparable trend was measured by Lüthi (1999) using similar methods on Sermeq Kujalleq (Jakobshavn Isbræ), with gap widths decreasing from $0.7-0.9 \mathrm{~mm}$ during a pumping test to $0.5 \mathrm{~mm}$ during the recovery phase. Similarly, pumping tests on a prism of simulated sediment installed beneath Engabreen yielded gap widths of $0.4-1.0 \mathrm{~mm}$ during pumping and $0.1-0.2 \mathrm{~mm}$ during recovery (Iverson and others, 2007). We interpret this decrease in hydraulic transmissivity and equivalent gap widths with time since breakthrough (Fig. 7) as evidence for progressive closure of gaps opened at the ice-sediment interface (in response to decreasing hydraulic head). Both our estimates, and those of Lüthi (1999) and Iverson and others (2007), are lower than those of $1.4-2.0 \mathrm{~mm}$ estimated from boreholes drilled on Whillans Ice Stream (formerly Ice Stream B) in West Antarctica; however, this may, at least partly, be explained by the earlier timing made possible by measuring pressure within the Whillans boreholes while they were drilled (Engelhardt and Kamb, 1997). The areal extent of the gap exerts a relatively weak control on gap width, with gap width approximately doubling for gaps occupying just one-tenth of the bed $(\phi$ $=0.1$; Table 4; Fig. 7). Other lines of evidence that support the gap opening hypothesis are discussed below.

The initial drop in hydraulic head in $\mathrm{BH} 19 \mathrm{e}$ was punctuated by a $14 \mathrm{~m}$ increase after $20 \pm 5 \mathrm{~s}$, which we interpret to be the arrival of the water from the $\mathrm{BH} 19 \mathrm{~g}$ breakthrough event through a gap 
Table 4. Summary of borehole response test results.

\begin{tabular}{|c|c|c|c|c|c|c|}
\hline \multirow[b]{2}{*}{ Test } & \multirow[b]{2}{*}{ Type (period) } & \multirow[b]{2}{*}{ Method } & \multirow{2}{*}{$\begin{array}{c}t \\
(\mathrm{~h})\end{array}$} & \multicolumn{2}{|c|}{$\delta(\mathrm{mm})$} & \multirow{2}{*}{$\begin{array}{c}T \\
\left(10^{-5} \mathrm{~m}^{2} \mathrm{~s}^{-1}\right)\end{array}$} \\
\hline & & & & $\phi=1$ & $\phi=0.1$ & \\
\hline $\mathrm{BH} 19 \mathrm{~g}(\mathrm{e})$ & Breakthrough & Hewitt and others (2018) ${ }^{a}$ & 0 & 0.69 & 1.48 & 14.56 \\
\hline $\mathrm{BH} 19 \mathrm{~g}(\mathrm{e})$ & Pumping (PT1) & Hewitt and others $(2018)^{b}$ & 0.9 & 0.56 & 1.21 & 7.96 \\
\hline $\mathrm{BH} 19 \mathrm{~g}(\mathrm{e})$ & Pumping (PT2) & Hewitt and others $(2018)^{b}$ & 1.7 & 0.44 & 0.95 & 3.93 \\
\hline $\mathrm{BH} 19 \mathrm{~g}(\mathrm{e})$ & Pumping (РT3) & Hewitt and others $(2018)^{b}$ & 1.9 & 0.24 & 0.51 & 0.62 \\
\hline $\mathrm{BH} 19 \mathrm{~g}(\mathrm{e})$ & Pumping (PT1) & Thiem (1906) & 0.9 & $0.32-0.47$ & $0.69-1.01$ & $1.51-4.75$ \\
\hline $\mathrm{BH} 19 \mathrm{~g}(\mathrm{e})$ & Pumping (PT2) & Thiem (1906) & 1.7 & $0.31-0.46$ & $0.67-0.99$ & $1.39-4.37$ \\
\hline $\mathrm{BH} 19 \mathrm{~g}(\mathrm{e})$ & Pumping (РT3) & Thiem (1906) & 1.9 & $0.31-0.45$ & $0.66-0.97$ & $1.31-4.13$ \\
\hline $\mathrm{BH} 19 \mathrm{c}$ & Recovery (early) & Weertman (1970) exponential fit & 4.9 & $0.18-0.20$ & $0.38-0.43$ & $0.25-0.35$ \\
\hline $\mathrm{BH} 19 \mathrm{e}$ & Recovery (early) & Weertman (1970) exponential fit & 4.4 & $0.16-0.18$ & $0.34-0.38$ & $0.18-0.26$ \\
\hline $\mathrm{BH} 19 \mathrm{~g}(\mathrm{e})$ & Recovery (early) & Weertman (1970) exponential fit & 4.4 & $0.16-0.18$ & $0.35-0.39$ & $0.19-0.28$ \\
\hline $\mathrm{BH} 19 \mathrm{C}$ & Recovery (late) & Cooper and Jacob (1946) & 14.1 & 0.19 & 0.40 & 0.30 \\
\hline $\mathrm{BH} 19 \mathrm{e}$ & Recovery (late) & Cooper and Jacob (1946) & 27.2 & 0.17 & 0.36 & 0.22 \\
\hline $\mathrm{BH} 19 \mathrm{~g}(\mathrm{e})$ & Recovery (late) & Cooper and Jacob (1946) & 23.0 & 0.18 & 0.39 & 0.28 \\
\hline
\end{tabular}

${ }^{a}$ Simplified model (Eqn (14)).

${ }^{b}$ Analytical solution (Eqn (23b)).

opened at the ice-sediment interface. The delayed arrival of the pressure increase demonstrates that no efficient hydraulic connection existed between $\mathrm{BH} 19 \mathrm{e}$ and $\mathrm{BH} 19 \mathrm{~g}$ prior to the breakthrough of BH19g. The $20 \pm 5 \mathrm{~s}$ delay between the start of the load increase on the drill tower and the start of the pressure increase in $\mathrm{BH} 19 \mathrm{e}$ gives a mean velocity of the pressure pulse of $0.20 \pm 0.04 \mathrm{~m} \mathrm{~s}^{-1}$. Similar pressure pulse propagation velocities of $0.08-0.18 \mathrm{~m}$ $\mathrm{s}^{-1}$ were observed on Whillans Ice Stream (Engelhardt and $\mathrm{Kamb}, 1997$ ). If a conduit existed between $\mathrm{BH} 19 \mathrm{~g}$ and $\mathrm{BH} 19 \mathrm{e}$ prior to breakthrough, the pressure pulse would be transmitted at the speed of sound $\left(1440 \mathrm{~m} \mathrm{~s}^{-1}\right)$ and attenuated in amplitude by the viscosity of water at a rate proportional to the gap width (Engelhardt and Kamb, 1997). The observed delay of $20 \pm 5 \mathrm{~s}$ is four orders of magnitude longer than the expected delay of a sound wave through $4.1 \mathrm{~m}$ of water of $0.003 \mathrm{~s}$, which confirms that no conduit existed between $\mathrm{BH} 19 \mathrm{~g}$ and $\mathrm{BH} 19 \mathrm{e}$ prior to breakthrough. Instead, we infer that the delay represents the propagation velocity of the gap tip outwards from $\mathrm{BH} 19 \mathrm{~g}$.

On the other hand, the disturbance in hydraulic head in BH19e caused by attempts to free a piezometer snagged at 394 $\mathrm{m}$ depth in $\mathrm{BH} 19 \mathrm{~g}$, demonstrates that a hydraulic connection between the two boreholes was present at this time $2.4 \mathrm{~h}$ after breakthrough (Fig. 5). The piezometer in $\mathrm{BH} 19 \mathrm{~g}$ was freed after repeated pulling on the cable, which caused the hydraulic head to fluctuate in $\mathrm{BH} 19 \mathrm{e}$, with disturbance continuing as the piezometer was lowered to the bed. We infer that this inter-borehole transmission of pressure perturbations indicates an open gap at the ice-sediment interface at this time.

The performance of the simplified Hewitt and others (2018) model in predicting the pressure response to borehole breakthrough provides further evidence for gap opening. The simplified model makes a reasonable prediction of the initial pressure response in $\mathrm{BH} 19 \mathrm{e}$ to $\mathrm{BH} 19 \mathrm{~g}$ breakthrough (Fig. 4). The model closely reproduces the small $(0.93 \mathrm{~m})$ drop in hydraulic head followed by the rapid rise within the first minute. This suggests that the small drop in $\mathrm{BH} 19 \mathrm{e}$ head can be explained by the propagation of a flexural wave through the ice that is faster than the spread of water. Furthermore, the initial drop in pressure indicates that the sediment is deformable because such a drop cannot be reproduced by the model if the sediment is rigid (see Fig. 7b of Hewitt and others, 2018). The model, however, predicts that the hydraulic head should reduce much more rapidly after the peak than was observed (Fig. 4a). Furthermore the analytical solution to the model (Eqn (23b)) predicts that $\partial h / \partial t$ should decrease non-linearly as $1 / t$, whereas the measured linear trends in hydraulic head during the pumping test suggest that $\partial h / \partial t$ was constant (Fig. 5). Both these disparities can be explained by gap opening.
The response of hydraulic head in $\mathrm{BH} 19 \mathrm{e}$ to $\mathrm{BH} 19 \mathrm{~g}$ breakthrough and pumping (Figs 4 and 5) resembles the idealised pressure response of petroleum reservoirs to hydraulic fracture treatment (cf. Fig. 18a of Hubbert and Willis, 1957). Specifically, the BH19g(e) breakthrough curve can be interpreted as a horizontal hydraulic fracture induced from a relatively smooth borehole, which is consistent with our interpretation of gap-opening at the ice-sediment interface induced by borehole breakthrough. We can therefore apply hydraulic fracture treatment theory to interpret the response to $\mathrm{BH} 19 \mathrm{~g}(\mathrm{e})$ breakthrough, as follows. After the initial drop in head, the arrival of water in $\mathrm{BH} 19 \mathrm{e}$ is marked by a steep rise (labelled A in Figs $4 \mathrm{a}$ and 5), and the gradient of this increase indicates compression of the water and subglacial sediment prior to the initiation of gap opening beyond $\mathrm{BH} 19 \mathrm{e}$. As gap opening begins the energy stored within the compressed water and sediment is transferred to gap propagation outwards from $\mathrm{BH} 19 \mathrm{e}$ resulting in more space for the water to occupy, and therefore lower pressure and a decrease in the gradient $(\mathrm{d} h / \mathrm{d} t$; label B). The peak in head after $130 \mathrm{~s}$ represents the transition from stable to unstable gap opening at the so-called 'breakdown pressure'. The ensuing transient head decrease (label C) can be explained by the gap opening rate transiently exceeding the water input rate, and by the diffusion of unevenly distributed pressure within the immature gap. With continued water input, a steady state of gap opening was reached resulting in the linear trend in hydraulic head (label D). In our pump tests, the recharge from the pump exceeded the discharge through the gap and the borehole filled with water at a linear rate determined by the supply rate from the pumps and the extraction rate of the drill hose. That water input exceeded water output during the pumping test despite discharge rates being much lower than during breakthrough provides evidence for partial gap closure in response to reduced water pressure. When the pumps ceased, head briefly stayed constant before dropping rapidly and then transitioning into a logarithmic decay representing gap closure and reversion to Darcian flow. In petroleum engineering, the pressure at the onset of the rapid drop (label E) has been interpreted to approximate the fracture propagation pressure. For $\mathrm{BH} 19 \mathrm{~g}(\mathrm{e})$ this occurs at $9.290 \mathrm{MPa}$, which is comparable to the ice overburden pressure (Table 1), and is thus consistent with hydraulic ice-sediment separation. This interpretation suggests that the application of hydraulic fracture models to borehole breakthrough and pumping tests would be an improvement over hydrogeological techniques such as the Thiem (1906) method, which inherently assume Darcian flow through an incompressible, isotropic aquifer. Such assumptions are unlikely to be valid if gap opening is taking place and this 


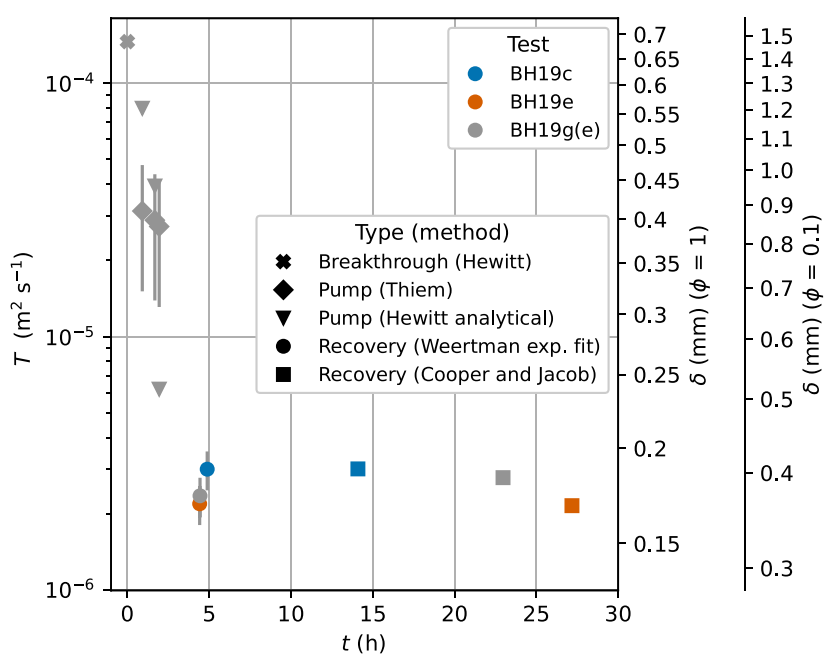

Fig. 7. Hydraulic transmissivity $(T)$ from multiple tests and methods plotted against time $(t)$ since respective breakthrough. The equivalent gap width $(\delta)$ is shown on the right-hand axes for gaps covering a range of fractions of the bed ( $\phi=1$ and $\phi=0.1$ ). Where appropriate, the range in the hydraulic transmissivity derived using radius of influence $R=10-70 \mathrm{~m}$ is shown by error bars.

may explain the difference between the Thiem (1906) and (analytical) Hewitt and others (2018) estimates of transmissivity during the pumping test (Table 4; Fig. 7).

The observation of an instantaneous drop in hydraulic head of $0.11 \mathrm{~m}$ in $\mathrm{BH} 19 \mathrm{c}$ in response to $\mathrm{BH} 19 \mathrm{~g}$ breakthrough without a subsequent increase in head (Fig. 4a) also cannot be reproduced by the simplified Hewitt and others (2018) model; the model predicts a flexural wave that would be apparent at any fixed radius as a small pressure drop followed by a large pressure rise. We hypothesise that the drop in pressure in $\mathrm{BH} 19 \mathrm{c}$ is caused by uplift at the $\mathrm{BH} 19 \mathrm{~g}$ injection site increasing the volume of a hydraulically-isolated cavity at $\mathrm{BH} 19 \mathrm{c}$, and that cavity expansion without an increase in water mass leads to a reduction in water density and pressure - that is a rarefaction. The simplified Hewitt and others (2018) model cannot reproduce rarefactions caused by stress transfer through the ice because it assumes that water compressibility is zero and, more fundamentally, it directly couples vertical displacement of the ice to the pressure in the subglacial environment, so that cavity expansion cannot occur without an increase in pressure (and vice versa). Further evidence for hydraulic isolation of the $\mathrm{BH} 19 \mathrm{c}$ cavity is provided by diurnal water pressure variations that are anti-correlated with those in BH19e and ice velocity (Figs 8a.b; e.g., Murray and Clarke, 1995; Meierbachtol and others, 2016; Lefeuvre and others, 2018). The inference of BH19c cavity isolation is also supported by the observation that diurnal pressure variations in $\mathrm{BH} 19 \mathrm{c}$ are manifested as small $\left(\sim 0.05^{\circ} \mathrm{C}\right.$ peak-to-peak) temperature cycles recorded at the base of BH19c (Fig. 8). This demonstrates that the water temperature quickly equilibrates with the pressure-dependent ice temperature, which would occur within an isolated cavity but not in a connected conduit. We would expect that within a connected conduit a throughput of water from different regions of the bed at variable pressures and temperatures would mask the small pressure-driven diurnal variations in temperature.

Rearranging the equation of state for water assuming mass is conserved and that temperature is constant, allows the pressure change to be related to the change in cavity volume

$$
\frac{V}{V_{0}}=\frac{1}{\exp \left[\beta_{\mathrm{w}}\left(p_{\mathrm{w}}-p_{\mathrm{w} 0}\right)\right]},
$$

where $V_{0}$ and $p_{\mathrm{w} 0}$ are the reference volume and pressure and $\beta_{\mathrm{w}}=$ $5.1 \times 10^{-10} \mathrm{~Pa}^{-1}$ is the compressibility of water. We can constrain

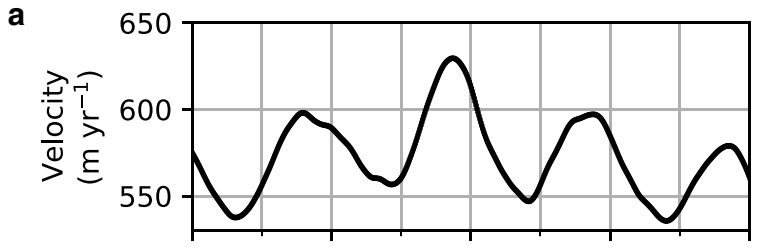

b

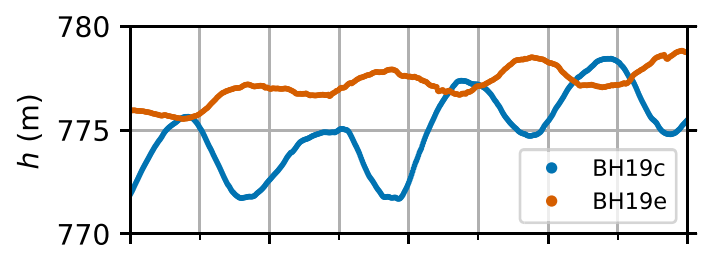

C

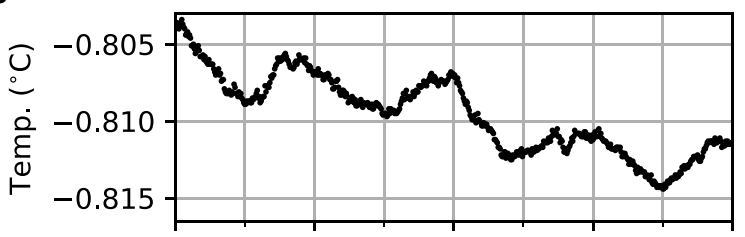

d

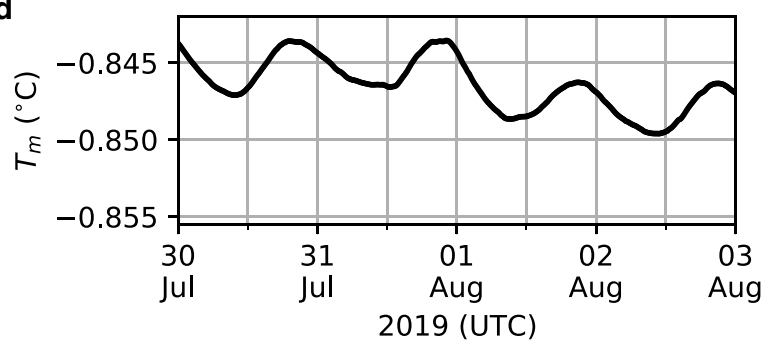

Fig. 8. Time series of (a) horizontal ice velocity, (b) hydraulic head in $\mathrm{BH} 19 \mathrm{C}$ and $\mathrm{BH} 19 \mathrm{e}$, (c) temperature at the base of $\mathrm{BH} 19 \mathrm{c}$, and (d) pressure-dependent melting temperature $T_{\mathrm{m}}$ calculated from the water pressure recorded in $\mathrm{BH} 19 \mathrm{c}$. Note that although the $y$-axes for (c) and (d) are offset the $y$-axis range is identical for both. The offset between measured temperature and $T_{\mathrm{m}}$ can be explained by uncertainties in the sensor installation depths and the Clausius-Clapeyron gradient.

the initial cavity geometry in two situations. First, the observation of no prior hydraulic connection between $\mathrm{BH} 19 \mathrm{e}$ and $\mathrm{BH} 19 \mathrm{~g}$, which were separated at the surface by $4.1 \mathrm{~m}$, indicates the $\mathrm{BH} 19 \mathrm{e}$ cavity was smaller than this distance. Second, the volume of water drained during $\mathrm{BH} 19 \mathrm{c}$ breakthrough and the hose raise of $15.6 \mathrm{~m}^{3}$ provides an approximate maximum constraint on the $\mathrm{BH} 19 \mathrm{c}$ cavity volume. These constraints are consistent with measurements of dye dilution in boreholes drilled on Isunnguata Sermia, which indicated cavity volumes of $7.6 \pm 6.7 \mathrm{~m}^{3}$ (Meierbachtol and others, 2016). Assuming the initial BH19c cavity volume was within the reasonable range of $0.5-15 \mathrm{~m}^{3}$ the small $0.11 \mathrm{~m}$ decrease in hydraulic head measured in $\mathrm{BH} 19 \mathrm{c}$ located $\sim 70 \mathrm{~m}$ distant can be explained by the contraction of the $\mathrm{BH} 19 \mathrm{c}$ cavity of $0.3-8.2 \times 10^{-6} \mathrm{~m}^{3}$. This demonstrates that, due to the low compressibility of water, the $0.11 \mathrm{~m}$ head decrease can be explained by a small cavity contraction of $5.5 \times 10^{-5} \%$. Hence, we hypothesise that hydraulic ice-sediment separation caused by the overpressure at the base of $\mathrm{BH} 19 \mathrm{~g}$ caused elastic uplift of the BH19c cavity roof. The $0.11 \mathrm{~m}$ drop in $\mathrm{BH} 19 \mathrm{c}$ head in response to $\mathrm{BH} 19 \mathrm{~g}$ breakthrough therefore provides direct evidence for the hypothesis of Murray and Clarke (1995) that pressure variations in hydraulically-isolated cavities occur due to elastic displacement of the ice roof driven by perturbations in hydraulically-connected regions of the bed. We discuss this further in Section 4.3.

\subsection{Hydraulic conductivity of subglacial sediments}

We interpret the decrease in hydraulic transmissivity with time since breakthrough (Table 4; Fig. 7) as evidence for the closure 
of a gap at the ice-sediment interface that was opened by the overpressure at borehole breakthrough. It is notable that hydraulic transmissivity estimates derived using the Cooper and Jacob (1946) recovery tests were relatively constant (that is within $8 \times$ $10^{-7} \mathrm{~m}^{2} \mathrm{~s}^{-1}$ ), despite the tests occurring over a wide range in time since breakthrough (14.1 - 27.2 h; Table 4; Fig. 7). Hence, these tests may be representative of Darcian flow through the sediment layer after gap closure. This suggestion is supported by the observation that the drawdown decreased logarithmically through time (Figs 6d-f) as is expected under Darcian flow, which is unlikely to be the case if gap closure was incomplete. Darcian flow through subglacial sediments was also inferred at site S30 from the initially logarithmic recovery in subglacial water electrical conductivity (EC) observed over $12 \mathrm{~h}$ following the dilution effect caused by drilling with low EC surface waters (Doyle and others, 2018).

When there is no flow through a gap at the ice-sediment interface, hydraulic transmissivity $(T)$ is the hydraulic conductivity $(K)$ integrated over the sediment thickness $b$

$$
T=b K
$$

The sediment thickness at the borehole location has been estimated at $20_{-2}^{+17} \mathrm{~m}$ by fibre-optic distributed acoustic seismics in BH19c (Booth and others, 2020). The full sediment thickness represents an upper limit for the calculation of hydraulic conductivity due to an increase in sediment compaction with depth, and the pressure-dependent depth limit to the diffusion of water from the ice-sediment interface (Tulaczyk and others, 2000). For the range of hydraulic transmissivity from the Cooper and Jacob (1946) recovery tests of $(2.2-3.0) \times 10^{-6} \mathrm{~m}^{2} \mathrm{~s}^{-1}$ (Table 4), and a range of reasonable 'hydraulically-active' sediment thicknesses of $2-20 \mathrm{~m}$, the hydraulic conductivity is $(0.1-1.5) \times 10^{-6} \mathrm{~m}$ $\mathrm{s}^{-1}$. This estimate is reasonable and within the range of hydraulic conductivities of glacial tills found in a range of settings by previous studies (Table 5). The Cooper and Jacob (1946) recovery test for $\mathrm{BH} 19 \mathrm{c}$ was performed several hours earlier with respect to the time of breakthrough than those in $\mathrm{BH} 19 \mathrm{e}$ and BH19g (Fig. 7) due to the earlier establishment of diurnal pressure variations in $\mathrm{BH} 19 \mathrm{c}$ (Fig. 3b). If gap closure was still taking place, this earlier timing could explain the slightly higher transmissivity derived for $\mathrm{BH} 19 \mathrm{c}$. We also cannot exclude the possibility that water flow during breakthrough and pumping tests - or from previous natural subglacial water flow - winnowed fine particles from the upper layer of sediment, increasing the hydraulic conductivity of this layer (Iverson and others, 2007; Fischer and others, 1998). As we cannot exclude winnowing, or be certain that the gap was fully closed, we interpret our estimates to represent an upper bound on the hydraulic conductivity of the sediment beneath this site.

Our inferred sediment hydraulic conductivity is two orders of magnitude higher than that determined from laboratory analysis of sediment retrieved from beneath Whillans Ice Stream (Engelhardt and others, 1990) and Trapridge Glacier in Canada (Murray and Clarke, 1995), see Table 5. A hydraulic conductivity of $10^{-7}-10^{-6} \mathrm{~m} \mathrm{~s}^{-1}$ is, however, broadly consistent with the type of glacigenic sediment within core samples taken from Uummannaq Fjord. These core samples comprise glacimarine sediments deposited during the last glacial maxima including matrix supported diamict with angular to sub-angular clasts of basalt and granitic gneiss dispersed throughout a sandy mud matrix (Ó'Cofaigh and others, 2013).

Laboratory measurements of the hydraulic conductivity of glacial sediments, which inherently measure only Darcian flow, are typically a few orders of magnitude lower than field measurements (Table 5; Hubbard and Maltman, 2000), a disparity that could, at least partly, be explained by residual gap opening at the ice-sediment interface during borehole response tests (e.g., Fountain, 1994; Stone and others, 1997). While in situ measurement of hydraulic conductivity of subglacial sediments appears to overestimate hydraulic conductivity under strict Darcian flow conditions, laboratory measurements provide little insight into the complexity of subglacial hydrological processes such as icesediment separation. Furthermore, as glacial sediment is by nature poorly sorted, with grain sizes ranging from boulders to clays, analysing samples that are large enough to be representative in laboratory experiments conducted at the scale necessary is more difficult than conducting in situ measurements (Clarke, 1987; Hubbard and Maltman, 2000). True subglacial water flow at this site may neither occur as entirely Darcian (laminar) flow through subglacial sediment nor exclusively through a gap at the ice-sediment interface, but rather a combination of the two. In any case, our in situ measurements represent a constraint on the effective hydraulic transmissivity that is independent of the process of water flow.

\subsection{Implications for subglacial hydrology and basal motion}

Subglacial water flow at glaciers underlain by porous sediment will naturally occur as laminar Darcian flow through interconnected pore spaces, although only insofar as the hydraulic transmissivity of the sediment is sufficient to accommodate the input of meltwater. With sustained inputs of water to the bed of many glaciers, from surface melt, for example, it may also be natural for a portion of that input to be stored temporarily in gaps opened at the ice-sediment interface, when water is delivered faster than it can permeate into the sediment below. The evidence presented herein demonstrates that the overpressure of a water-filled borehole can open a gap at the ice-sediment interface and need not directly intersect an active subglacial drainage system in order to drain. The delayed arrival of the pressure pulse in $\mathrm{BH} 19 \mathrm{e}$ rules out the existence of sheet flow (Weertman, 1970; Alley and others, 1986; Creyts and Schoof, 2009), efficient conduits such as R-channels or canals (e.g., Röthlisberger, 1972; Walder and Fowler, 1994; Ng, 2000), and linked cavities (e.g., Kamb, 1987) prior to BH19g breakthrough, but supports the gap-opening theory of Engelhardt and Kamb (1997). We infer that prior to the breakthrough of $\mathrm{BH} 19 \mathrm{~g}$, subglacial drainage at this location consisted exclusively of Darcian flow through subglacial sediments with a hydraulic conductivity $K \leq 10^{-6} \mathrm{~m} \mathrm{~s}^{-1}$.

Borehole drainage at the ice-sediment interface may be physically similar, but of lower magnitude, to that which occurs during the subglacial drainage of proglacial (Sugiyama and others, 2008), subglacial (e.g., Jóhannesson, 2002) and supraglacial lakes (Tsai and Rice, 2010, 2012; Doyle and others, 2013; Dow and others, 2015; Stevens and others, 2015; Hewitt and others, 2018) via a broad, turbulent and transient sheet. We note that gap opening at the ice-sediment or ice-bedrock interface is conceptually the same as horizontal hydraulic fracture at this interface as envisaged by previous studies (Tsai and Rice, 2010, 2012; Hewitt and others, 2018). Rapid water flow into this narrow gap is likely to be turbulent (Section 3.1.1); however, flow must become laminar near the gap tip as the width of the gap decreases to zero, and flow velocity will also decrease with distance from the injection point (Hewitt and others, 2018). Continued sheet flow through a uniform gap would be unstable as irregularities in flow would theoretically favour the formation of conduits through preferential sediment erosion and concentrated ice melt from frictional heat (Röthlisberger, 1972; Walder and Fowler, 1994; Ng, 2000). Conduit development beneath kilometre-thick ice is, however, anticipated to require continuous water supply at high pressure over prolonged periods, which may only occur if there is 
Table 5. Selected hydraulic conductivities of glacial sediments from the literature in ascending order. Sediments at the lower end of the scale $\left(K \leq 10^{-4} \mathrm{~m} \mathrm{~s} \mathrm{~s}^{-1}\right)$ were typically interpreted as unconsolidated sands and gravels, often associated with water flow from subglacial channels winnowing fine particles (Fischer and others, 1998).

\begin{tabular}{|c|c|c|}
\hline$K\left(\mathrm{~m} \mathrm{~s}^{-1}\right)$ & Location (method) & Source \\
\hline $10^{-12}-10^{-6}$ & Literature review of glacial tills & Freeze and Cherry (1979) \\
\hline $10^{-12}-10^{-9}$ & Haut Glacier d'Arolla, Switzerland (laboratory measurement) & Hubbard and Maltman (2000) \\
\hline $10^{-11}-10^{-9}$ & Coastal exposure of glacial till, Traeth y Mwnt, Wales (laboratory measurement) & Hubbard and Maltman (2000) \\
\hline $10^{-9}$ & Whillans Ice Stream, Antarctica (laboratory measurement) & Engelhardt and others (1990) \\
\hline $10^{-9}$ & Trapridge Glacier, Canada (analysis of pressure freezing curves) & Waddington and Clarke (1995) \\
\hline $10^{-9}-10^{-8}$ & Storglaciaren, Sweden (pressure wave propagation) & Fischer and others (1998) \\
\hline $10^{-8}$ & Storglaciaren, Sweden (laboratory measurement) & Iverson and others (1994) \\
\hline $10^{-8}$ & Trapridge Glacier, Canada (laboratory measurement) & Murray and Clarke (1995) \\
\hline $10^{-7}-10^{-6}$ & Sermeq Kujalleq (Store Glacier), Greenland (borehole response tests) & This study \\
\hline $10^{-7}-10^{-5}$ & Surface-exposures of glacial till, Snowy Range, Wyoming (infiltration tests) & Ronayne and others (2012) \\
\hline $10^{-7}-10^{-4}$ & Haut Glacier d'Arolla, Switzerland (diurnal pressure wave propagation) & Hubbard and others (1995) \\
\hline $10^{-7}-10^{-4}$ & South Cascade Glacier, USA (diurnal pressure wave propagation) & Fountain (1994) \\
\hline $10^{-6}$ & Breidamerkurjökull, Iceland (laboratory measurement) & Boulton and Dent (1974) \\
\hline $10^{-5}$ & Midre Lovenbreen, Svalbard (slug tests) & Kulessa and Murray (2003) \\
\hline $10^{-4}$ & Trapridge Glacier, Canada (breakthrough response tests) & Stone and others (1997) \\
\hline $10^{-3}$ & Bakaninbreen, Svalbard (slug tests) & Kulessa and Murray (2003) \\
\hline $10^{-3}-10^{-2}$ & Haut Glacier d'Arolla, Switzerland (slug tests) & Kulessa and others (2005) \\
\hline $10^{-2}$ & Gornergletscher, Switzerland (slug tests) & Iken and others (1996) \\
\hline
\end{tabular}

continued water input from the surface (e.g., Dow and others, 2014, 2015). Hence, our inference of complete, or at least partial, gap closure in response to declining pressure is consistent with existing theory as the water volumes provided by borehole drainage and subsequent pumping $\left(\sim 15 \mathrm{~m}^{3}\right)$ are likely insufficient to establish an efficient conduit beneath kilometre-thick ice. The development of efficient conduits in response to borehole breakthrough can also be excluded by the low discharge rate of $8.4 \times 10^{-5} \mathrm{~m}^{3} \mathrm{~s}^{-1}$ calculated from the $45 \mathrm{~h}$ required for hydraulic head to recover to the equilibrium level following the injection of $13.6 \mathrm{~m}^{3}$ of water at $\mathrm{BH} 19 \mathrm{~g}$ breakthrough and during the drill stem raise. Although we cannot rule out the persistence of stable sheet flow following borehole drainage facilitated by clasts partially supporting the ice overburden pressure (Creyts and Schoof, 2009), our observations of a progressive decrease in hydraulic transmissivity can be entirely explained by gap closure and a reversion to Darcian flow through the sediment layer. For simplicity, this and previous studies (Tsai and Rice, 2010, 2012; Hewitt and others, 2018) make the reasonable assumption that initial gap opening is elastic; however, where temperate ice is present, as it is at R30, viscous deformation cannot be neglected during the longer time scales of pumping tests or lake drainage events (Appendix C). The application of a viscoelastic model (e.g., Reeh and others, 2003) to borehole response tests (and lake drainage events) would therefore represent an improvement over the analysis presented herein (and previously).

The instantaneous $0.11 \mathrm{~m}$ drop in $\mathrm{BH} 19 \mathrm{c}$ head in response to BH19g breakthrough (Fig. 4a) provides direct evidence for the hypothesis of Murray and Clarke (1995) that pressure variations can be transmitted to unconnected cavities through elastic displacement of the ice roof. Murray and Clarke (1995) theorised that uplift caused by high water pressure relieves the pressure in adjacent hydraulically-isolated cavities. This hypothesis is one of three hypotheses of mechanical forcing of water pressure that have been proposed to explain the often observed diurnal variation of water pressure in hydrologically-isolated cavities that is out of phase with both ice velocity and water pressure in boreholes and moulins deemed to be connected to efficient subglacial conduits (Murray and Clarke, 1995; Engelhardt and Kamb, 1997; Gordon and others, 1998; Dow and others, 2011; Andrews and others, 2014; Ryser and others, 2014; Lefeuvre and others, 2015; Meierbachtol and others, 2016; Rada and Schoof, 2018). While we cannot rule out the possibility that such anti-correlated diurnal pressure and velocity variations in $\mathrm{BH} 19 \mathrm{c}$ (Fig. 8) can be attributed to the alternative hypotheses of cavity expansion and contraction caused by longitudinal strain (Ryser and others, 2014) or basal sliding (Iken and Truffer, 1997; Bartholomaus and others, 2011; Hoffman and Price, 2014), displacement of the ice roof due to elastic uplift during gap-opening at $\mathrm{BH} 19 \mathrm{~g}$ breakthrough can entirely explain the $0.11 \mathrm{~m}$ instantaneous drop in $\mathrm{BH} 19 \mathrm{c}$ head. It is therefore plausible that elastic displacement of the ice roof by diurnal pressure variations within a nearby conduit also explains the anti-correlated diurnal variations in $\mathrm{BH} 19 \mathrm{c}$ pressure. This assertion is supported by three-dimensional full-Stokes modelling (Lefeuvre and others, 2018) that reproduced anti-correlated pressure variations between connected and unconnected components of the subglacial drainage system without invoking cavity expansion caused by sliding.

Similar to borehole breakthrough events, we argue that water flow at the ice-sediment interface may also occur at times of naturally high subglacial water pressures. It is important to note that the gap widths we report are probably larger than would have occurred naturally for the same volume of cold glacial water because warm drilling water would have enlarged the gaps through ice melt. The greater variability in meltwater supply means that gap opening at the ice-sediment interface is more likely to occur naturally on the Greenland Ice Sheet, and on mountain glaciers, than on the West Antarctic ice streams where the process was originally inferred (Engelhardt and Kamb, 1997). Hence, gap opening at the ice-sediment interface has important implications for our understanding of subglacial hydrological systems that extends beyond its ability to explain the drainage of boreholes. Subglacial hydrology in ice-sheet models may for instance include exchanges of water flowing partly at the interface and partly within subglacial sediment, which has proven efficient in reproducing day-to-day variations in ice flow as observed at the land-terminating southwest ice margin (Bougamont and others, 2014). Darcian flow and gap-opening therefore provide a physical explanation for the partitioning of water flowing at the interface and within subglacial sediment.

Gap-opening may also play a role in the formation and growth of subglacial drainage systems. Within the framework of existing theory, gap opening provides the initial conduit that may later develop into an inefficient narrow orifice in a distributed (i.e. linked cavity) drainage system (Kamb, 1987), which may ultimately develop into an efficient channel or canal (Röthlisberger, 1972; Walder and Fowler, 1994; Ng, 2000). That the overpressure of a water-filled vertical conduit stretching from the surface to the 
bed (i.e. a borehole) can open a gap at the ice-sediment interface, despite the low volumes of water involved, has implications for the establishment of subglacial drainage of the much larger water volumes supplied via moulins, crevasses and supraglacial lakes. It illustrates the manner in which regions of the basal environment can become hydrologically connected during peaks in water pressure. Hence, gap opening can explain transient periods of borehole water pressure synchroneity that abruptly punctuate the often observed long-term pattern of anti-correlated variations in water pressure and velocity measured in hydraulically-isolated cavities during periods of high water pressure (e.g., Murray and Clarke, 1995; Engelhardt and Kamb, 1997; Harper and others, 2007; Andrews and others, 2014; Rada and Schoof, 2018). If areas of the bed that were previously hydraulically isolated experience net drainage as a result of gap opening at the ice-sediment interface, it may also explain the hydro-mechanical regulation of ice flow (e.g., Sole and others, 2013; Tedstone and others, 2015; Davison and others, 2020), which observations suggest cannot be entirely explained by water pressures within efficient channels (Andrews and others, 2014). It follows that drainage at the icesediment interface and Darcian flow through sediments with a low hydraulic conductivity may be two of potentially multiple processes behind the hypothesised weakly-connected component of the subglacial drainage system (Hoffman and others, 2016).

A drainage system consisting of cavities, which we assume are present at the base of our boreholes, linked via gaps opened at the ice-sediment interface would at first appear similar to the linked cavity theory of glacial drainage, which consists of cavities connected via narrow orifices (e.g., Kamb, 1987). There is, however, an important distinction in that the linked cavity model specifies that orifices are continuously open and water flow is inefficient and turbulent due to the length and narrowness of orifices (Kamb, 1987). Modification of the linked cavity theory to allow transient gap opening between cavities under high water pressure with turbulent flow would explain the same characteristics associated with linked cavity drainage systems: enhanced basal motion, sediment entrainment (as indicated by increased turbidity) and increased connectivity of the bed at times of high water pressure. It would also explain the existence of neighbouring yet behaviourally-independent subglacial drainage subsystems in close proximity (e.g., Murray and Clarke, 1995; Harper and others, 2007; Rada and Schoof, 2018), which the majority of previous models of subglacial drainage cannot reproduce as they inherently allow water to diffuse across the entire glacier bed (e.g., Schoof, 2010; Hewitt, 2013; Werder and others, 2013). This implies a strong link between subglacial hydrology, stresses within the ice and basal motion that will be challenging to reproduce within numerical models due to the requirement to combine linear-elastic gap opening with a viscous ice rheology.

To date, every borehole drilled on Sermeq Kujalleq (Store Glacier) drained rapidly and immediately upon reaching the bed. This includes three boreholes at R30 in 2019, four boreholes at R29 in 2018 (unpublished), and seven boreholes at S30 in 2014 and 2016 (Doyle and others, 2018). A similar pattern of rapid borehole drainage, with a small number of exceptions, has been reported for Whillans Ice Stream in West Antarctica (Engelhardt and Kamb, 1997) and Sermeq Kujalleq (Jakobshavn Isbræ) in West Greenland (Lüthi, 1999). While the results presented here provide further evidence for gap opening as a mechanism for rapid borehole drainage, it also raises the question of why some boreholes on other ice masses do not drain rapidly upon reaching the bed. Some boreholes appear to never drain (e.g., Smart, 1996), while others drain slowly (e.g., Andrews and others, 2014), and others drain after a delay (e.g., Gordon and others, 2001; Kamb and Engelhardt, 1987; Engelhardt and Kamb, 1997; Fischer and Clarke, 2001). This heterogeneity, which often occurs within the same field site, could be explained by the stress regime, boreholes terminating blind in debris-rich basal ice before they are able to connect to the subglacial drainage system, or by the presence of impermeable barriers such as areas of ice-bedrock contact or cold ice, the latter of which can occur even within predominantly temperate glaciers (Robin, 1976). A detailed discussion of the heterogeneity of borehole drainage is not warranted here (see instead Smart, 1996 and Gordon and others, 2001), but we do seek an explanation for the homogeneity in borehole drainage observed to date on Sermeq Kujalleq (Store Glacier). Hot water drilling is ineffective at penetrating debris-rich basal ice, which is characteristic of many exposed margins of the Greenland Ice Sheet, for example, on Russell Glacier (Knight and others, 2002) and at the base of icebergs discharging from Sermeq Kujalleq (Jakobshavn Isbræ; Lüthi and others, 2009), yet none of the boreholes drilled to date on Sermeq Kujalleq (Store Glacier) terminated above the bed due to an obstruction by englacial clasts. We therefore speculate (while noting the small number of boreholes drilled at a limited number of sites) that debris content within basal ice on Sermeq Kujalleq (Store Glacier) may be low. If so, this could be explained by the removal of debris-rich basal ice formed upstream by basal melt. Furthermore, low (and potentially even negative) effective pressures (e.g. $-46 \pm 102 \mathrm{kPa}$ at R30; Table 1) are conducive to hydraulic ice-bed separation (e.g., Schoof and others, 2012) and these conditions are found at all the Sermeq Kujalleq (Store Glacier) sites drilled to date. Modelling of subglacial drainage through a poroelastic sediment and cavity suggests that elastic gap opening is enabled by the suction of water from an underlying porous sediment layer without the requirement for a pre-wetted water film (Hewitt and others, 2018). We therefore conclude that rapid borehole drainage on Sermeq Kujalleq (Store Glacier) is facilitated by low effective pressures, subglacial sediment, and a potentially low debris content within basal ice.

Booth and others (2020) used the low basal reflectivity in vertical seismic profiles to infer that the subglacial sediment layer at site R30 has an acoustic impedance similar to that of basal ice, and from this, they suggested that the sediment is consolidated, and neither deforming nor lithified. The inference that the sediment layer is not deforming implies that the fast ice velocity at this site must be accommodated by either enhanced internal deformation of the ice, ice-sediment decoupling under high water pressure (e.g., Iverson and others, 1995, 2007), or deformation of a sediment layer thinner than the $5-10 \mathrm{~m}$ vertical resolution of the seismic technique. With regard to the last assertion we note that sediment deformation often occurs within an upper layer that is typically only decimetres to a few metres thick (e.g., Clarke, 1987; Murray, 1997; Humphrey and others, 1993; Engelhardt and Kamb, 1998), and that the shape of the pressure pulse during $\mathrm{BH} 19 \mathrm{~g}$ breakthrough can only be reproduced using the model of Hewitt and others (2018) if the sediment layer is deformable. While the extent of sediment deformation beneath this site remains inconclusive the evidence presented herein supports the hypothesis of ice-sediment decoupling under periods of high water pressure. Indeed, we suggest that the theory of gap opening at the ice-sediment interface (Engelhardt and Kamb, 1997) may involve the same physical process as ice-sediment decoupling envisaged by Iverson and others (1995). To explain the reverse tilt of inclinometers just below the ice-sediment interface, Iverson and others (1995) envisaged that sediment would be squeezed into the zone of uplift at times of high water pressure. The modulation of slip by pressurised water at the ice-sediment interface was confirmed by pump tests on a simulated prism of till on Engabreen (Iverson and others, 2007). Further evidence for gap opening and decoupling at the ice-sediment interface is provided by (as far as we are aware) unrepeated, direct observation of a $\mathrm{cm}$-wide gap at the ice-sediment interface of Blue 
Glacier, USA (Engelhardt and others, 1978). Borehole photography revealed a $\sim 0.1 \mathrm{~m}$ thick sediment layer overlying bedrock that was mechanically and visibly distinct from a $0.1-16.0 \mathrm{~m}$ thick debris-laden basal ice layer. Engelhardt and others (1978) suggested that the gap was opened by the overpressure of the water-filled borehole and that basal sliding velocities were faster where gaps were present. They also inferred that interstitial pressure within the sediment must be close to or at the ice overburden pressure in order to prevent the basal ice merging with the sediment layer through regelation, an assertion supported by Rempel (2008). Hence, further in situ observations are required to investigate whether ice-sediment decoupling occurs via a gap at the icesediment interface or through an increase in the thickness of the sediment layer as proposed by Iverson and others (1995), or a combination of both processes as modelled by Hewitt and others (2018).

\section{Conclusions}

Detailed measurements of pressure pulses during a borehole breakthrough event, and a decrease in hydraulic transmissivity with time since breakthrough, provide evidence for hydraulic gap opening and closure at the ice-sediment interface, with gaps opening and closing in response to water pressure. Analysis of the subsequent recovery of subglacial water pressure indicates that the hydraulic conductivity of the subglacial sediment layer is on the order of $10^{-7}-10^{-6} \mathrm{~m} \mathrm{~s}^{-1}$, which suggests it is coarsegrained and more permeable than the fine-grained sediments beneath West Antarctic ice streams. As seismic surveys suggest that sediment at this site is not deforming, we infer that fast basal motion may be accommodated by ice-sediment decoupling and potentially shallow-depth sediment deformation in a layer thinner than the $5-10 \mathrm{~m}$ resolution of the seismic technique.

Observations of a pressure drop simultaneous with the breakthrough of a borehole $70 \mathrm{~m}$ away provides direct evidence for the hypothesis that anti-correlations between water pressure in connected and unconnected regions of the bed can be explained via elastic displacement of the ice roof.

We argue that water flow via gaps opened at the ice-sediment interface is likely to play a critical role in both basal motion and the development of subglacial hydrology on soft-bedded ice masses, and that Darcian flow through sediments may explain the drainage and recharge of areas of the bed that are otherwise hydrologically isolated.

Supplementary material. The supplementary material for this article can be found at https://doi.org/10.1017/jog.2021.121.

Data. The data sets presented in this paper are available for download from https://doi.org/10.6084/m9.figshare.16838020.

Acknowledgements. This research was funded by the European Research Council as part of the RESPONDER project under the European Union's Horizon 2020 research and innovation program (Grant 683043). T.R.C. and R.L. were supported by Natural Environment Research Council Doctoral Training Partnership Studentships (Grant NE/L002507/1). We thank Lee Greenler for providing the code for modelling borehole diameter; Katie Miles, Emma Docherty and Tom Chase for assistance in the construction of borehole sensor strings; and Sean Peters, Mickey MacKie, Mike Prior-Jones, Eliza Dawson and Tun Jan Young for assistance in the field. We are very grateful to Ann Andreasen and the Uummannaq Polar Institute for their kind hospitality. Comments from the Scientific Editor, Ali Graham, B. de Fleurian and two anonymous reviewers resulted in significant improvements to this paper.

Author contributions. The overall research project (RESPONDER) was led by P.C., with B.H. leading the hot water drilling and borehole instrumentation reported herein. Data collection was led by S.D., with contributions from B.H., P.C., R.L., C.S. and T.C. S.D. conducted the data analysis. R.L. adapted and ran the borehole drilling model. T.C. surveyed the borehole positions and led site mapping. D.H. and J.N. calculated the breakthrough volumetric flux and pressure response. The manuscript was written by S.D., with contributions from all co-authors.

\section{References}

Alley R, Blankenship D, Bentley C and Rooney S (1986) Deformation of till beneath Ice Stream B, West Antarctica. Nature 322, 57-59. doi: 10.1038/ $322057 \mathrm{a} 0$.

Alley R, Blankenship D, Rooney S and Bentley C (1989) Water-pressure coupling of sliding and bed deformation: III. Application to Ice Stream B, Antarctica. Journal of Glaciology 35(119), 130-139. doi: 10.3189/002214389793701572

Alley RB, Cuffey KM and Zoet LK (2019) Glacial erosion: status and outlook. Annals of Glaciology 60(80), 1-13. doi: 10.1017/aog.2019.38

Andrews LC and 7 others (2014) Direct observations of evolving subglacial drainage beneath the Greenland Ice Sheet. Nature 514(7520), 80-83. doi: 10.1038 /nature 13796

Bartholomaus T, Anderson R and Anderson S (2011) Growth and collapse of the distributed subglacial hydrologic system of Kennicott Glacier, Alaska, USA, and its effects on basal motion. Journal of Glaciology $\mathbf{5 7}$ (206), 985-1002. doi: 10.3189/002214311798843269

Blankenship DD, Bentley CR, Rooney ST and Alley RB (1986) Seismic measurements reveal a saturated porous layer beneath an active Antarctic ice stream. Nature 322(6074), 54-57. doi: 10.1038/322054a0

Booth AD and 8 others (2020) Distributed acoustic sensing of seismic properties in a borehole drilled on a fast-flowing Greenlandic outlet glacier. Geophysical Research Letters 47(13), e2020GL088148. doi: 10.1029/2020GL088148.

Bougamont $\mathbf{M}$ and 5 others (2014) Sensitive response of the Greenland Ice Sheet to surface melt drainage over a soft bed. Nature Communications 5, 5052. doi: $10.1038 /$ ncomms6052

Boulton GS and Dent D (1974) The nature and rates of post-depositional changes in recently deposited till from south-east Iceland. Geografiska Annaler: Series A, Physical Geography 56(3-4), 121-134. doi: 10.1080/ 04353676.1974.11879894

Christianson K and 7 others (2014) Dilatant till facilitates ice-stream flow in northeast Greenland. Earth and Planetary Science Letters 401(0), 57-69. doi: 10.1016/j.epsl.2014.05.060

Chudley TR and 7 others (2019b) Supraglacial lake drainage at a fast-flowing Greenlandic outlet glacier. Proceedings of the National Academy of Sciences 116(51), 25468-25477. doi: 10.1073/pnas.1913685116.

Chudley TR, Christoffersen P, Doyle SH, Abellan A and Snooke N (2019a) High-accuracy UAV photogrammetry of ice sheet dynamics with no ground control. The Cryosphere 13(3), 955-968. doi: 10.5194/tc-13-955-2019

Clarke GKC (1987) Subglacial till: a physical framework for its properties and processes. Journal of Geophysical Research: Solid Earth 92(B9), 9023-9036. doi: 10.1029/JB092iB09p09023

Cooper H and Jacob C (1946) A generalized graphical method for evaluating formation constants and summarizing well field history. American Geophysical Union Transactions 27, 526-534. doi: 10.1029/TR027i004p00526

Creyts TT and Schoof CG (2009) Drainage through subglacial water sheets. Journal of Geophysical Research: Earth Surface 114(F4), F04008. doi: 10. 1029/2008JF001215.

Cuffey K and Paterson W (2010) The Physics of Glaciers. 4th ed.: Elsevier.

Davison BJ and 6 others (2020) Subglacial drainage evolution modulates seasonal ice flow variability of three tidewater glaciers in southwest Greenland. Journal of Geophysical Research: Earth Surface 125(9), e2019JF005492. doi: 10.1029/2019JF005492.

de Marsily G (1986) Quantitative Hydrogeology. Orlando, Florida: Academic Press Inc..

Dow CF and 10 others (2015) Modeling of subglacial hydrological development following rapid supraglacial lake drainage. Journal of Geophysical Research: Earth Surface 120, 1127-1147. doi: 10.1002/2014JF003333.

Dow C, Kavanaugh J, Sanders J, Cuffey K and MacGregor K (2011) Subsurface hydrology of an overdeepened cirque glacier. Journal of Glaciology 57(206), 1067-1078. doi: 10.3189/002214311798843412

Dow C, Kulessa B, Rutt I, Doyle S.H and Hubbard A (2014) Upper bounds on subglacial channel development for interior regions of the Greenland ice sheet. Journal of Glaciology 60(224), 1044-1052. doi: 10.3189/2014JoG14J093

Doyle S and 9 others (2013) Ice tectonic deformation during the rapid in situ drainage of a supraglacial lake on the Greenland Ice Sheet. The Cryosphere 7(1), 129-140. doi: 10.5194/tc-7-129-2013 
Doyle SH and 7 others (2018) Physical conditions of fast glacier flow: 1. Measurements from boreholes drilled to the bed of Store Glacier, West Greenland. Journal of Geophysical Research: Earth Surface 123(2), 324348. doi: 10.1002/2017JF004529

Engelhardt H (1978) Water in glaciers: observations and theory of the behaviour of water levels in boreholes. Zeitschrift für Gletscherkunde und Glazialgeologie. 14, 35-60.

Engelhardt HF, Harrison WD and Kamb B (1978) Basal sliding and conditions at the glacier bed as revealed by borehole photography. Journal of Glaciology 20(84), 469-508. doi: 10.3198/1978JoG20-84-469-508

Engelhardt H, Humphrey N, Kamb B and Fahnestock M (1990) Physical conditions at the base of a fast moving Antarctic ice stream. Science, 248 (4951), 57-59. doi: 10.1126/science.248.4951.57

Engelhardt H and Kamb B (1997) Basal hydraulic system of a West Antarctic ice stream: constraints from borehole observations. Journal of Glaciology 43 (144), 207-229. doi: 10.3198/1997JoG43-144-207-230

Engelhardt H and Kamb B (1998) Basal sliding of Ice Stream B, West Antarctica. Journal of Glaciology 44(147), 223-230. doi: 10.3189/ S0022143000002562

Fischer UH and Clarke GK (2001) Review of subglacial hydro-mechanical coupling: Trapridge Glacier, Yukon Territory, Canada. Quaternary International 86(1), 29-43. doi: 10.1016/S1040-6182(01)00049-0

Fischer UH, Iverson NR, Hanson B, LeB Hooke R and Jansson P (1998) Estimation of hydraulic properties of subglacial till from ploughmeter measurements. Journal of Glaciology 44(148), 517-522. doi: 10.3189/ S0022143000002033

Flowers G and Clarke G (2002) A multicomponent coupled model of glacier hydrology 1 . Theory and synthetic examples. Jounal of Geophysical Research 107(B11). doi: 10.1029/2001JB001122

Fountain A (1994) Borehole water-level variations and implications for the subglacial hydraulics of South Cascade Glacier, Washington State, USA. Journal of Glaciology 40(135), 293-304. doi: 10.3189/S0022143000007383

Freeze RA and Cherry JA (1979) Groundwater. Englewood Cliffs, N.J, Prentice-Hall Inc.

Gordon S and 5 others (1998) Seasonal reorganization of subglacial drainage system of Haut Glacier d'Arolla, Valais, Switzerland, inferred from measurements in boreholes. Hydrological Processes 12, 105-133.

Gordon S and 7 others (2001) Borehole drainage and its implications for the investigation of glacier hydrology: experiences from Haut Glacier d'Arolla, Switzerland. Hydrological Processes 15, 797-813. doi: 10.1002/hyp.184

Greenler L and 6 others (2014) Modeling hole size, lifetime and fuel consumption in hot-water ice drilling. Annals of Glaciology 55(68), 115-123. doi: 10.3189/2014AoG68A033

Harper J, Humphrey N, Pfeffer W and Lazar B (2007) Two modes of accelerated glacier sliding related to water. Geophysical Research Letters 34, L12503. doi: 10.1029/2007GL030233

Haseloff M, Hewitt IJ and Katz RF (2019) Englacial pore water localizes shear in temperate ice stream margins. Journal of Geophysical Research: Earth Surface 124(11), 2521-2541. doi: 10.1029/2019JF005399

Hewitt I (2013) Seasonal changes in ice sheet motion due to melt water lubrication. Earth and Planetary Science Letters 371-372, 16-25. doi: 10.1016/j. epsl.2013.04.022

Hewitt DR, Chini GP and Neufeld JA (2018) The influence of a poroelastic till on rapid subglacial flooding and cavity formation. Journal of Fluid Mechanics 855, 1170-1207. doi: 10.1017/jfm.2018.624

Hiscock K and Bense V (2014) Hydrogeology: Principles and Practice. 2nd ed. Chichester, West Sussex, UK: Wiley-Blackwell.

Hodge SM (1979) Direct measurement of basal water pressures: progress and problems. Journal of Glaciology 23(89), 309-319. doi: 10.3189/S0022143000029920

Hoffman MJ and 9 others (2016) Greenland subglacial drainage evolution regulated by weakly connected regions of the bed. Nature Communications 7, 13903. doi: 10.1038/ncomms 13903.

Hoffman M and Price S (2014) Feedbacks between coupled subglacial hydrology and glacier dynamics. Journal of Geophysical Research: Earth Surface 119(3), 414-436. doi: 10.1002/2013JF002943

Hofstede C and 7 others (2018) Physical conditions of fast glacier flow: 2. Variable extent of anisotropic ice and soft basal sediment from seismic reflection data acquired on Store Glacier, West Greenland. Journal of Geophysical Research: Earth Surface 123(2), 349-362. doi: 10.1002/2017JF004297

Hubbard B and 6 others (2021) Borehole-based characterization of deep mixed-mode crevasses at a greenlandic outlet glacier. AGU Advances 2 (2), e2020AV000291. doi: 10.1029/2020AV000291.
Hubbard B and Maltman A (2000) Laboratory investigations of the strength, static hydraulic conductivity and dynamic hydraulic conductivity of glacial sediments, In: Maltman, A., Hubbard, B., and Hambrey, M.J. Deformation of Glacial Materials 176, 231-242.

Hubbard B, Sharp M, Willis I, Nielsen M and Smart C (1995) Borehole water-level variations and the structure of the subglacial hydrological system of Haut Glacier d'Arolla, Valais, Switzerland. Journal of Glaciology 41(139), 572-583. doi: 10.3189/S0022143000034894

Hubbert MK and Willis DG (1957) Mechanics of hydraulic fracturing. Transactions of the AIME 210(01), 153-168.

Humphrey N, Kamb B, Fahnestock M and Engelhardt H (1993) Characteristics of the bed of the lower Columbia Glacier, Alaska. Journal of Geophysical Research: Solid Earth 98(B1), 837-846. doi: 10.3189/002214390793701354

Hutter K (1983) Theoretical glaciology: material science of ice and the mechanics of glaciers and ice sheets. Tokyo: D Reidel, Dordrecht/Terra Scientific.

Iken A and Bindschadler R (1986) Combined measurements of subglacial water pressure and surface velocity of Findelengletscher, Switzerland: conclusions about drainage system and sliding mechanisms. Journal of Glaciology 32(110), 101-119. doi: 10.3189/S0022143000006936

Iken A, Fabri K and Funk M (1996) Water storage and subglacial drainage conditions inferred from borehole measurements on Gornergletscher, Valais, Switzerland. Journal of Glaciology 42(141), 233-248. doi: 10.3189/ S0022143000004093

Iken A and Truffer M (1997) The relationship between subglacial water pressure and velocity of Findelengletscher, Switzerland, during its advance and retreat. Journal of Glaciology 43(144), 328-338. doi: 10.3189/ S0022143000003282

Iverson N and 7 others (2007) Soft-bed experiments beneath Engabreen, Norway: regelation infiltration, basal slip and bed deformation. Journal of Glaciology 53(182), 323-340. doi: 10.3189/002214307783258431

Iverson N, Hanson B, Hooke RL and Jansson P (1995) Flow mechanism of glaciers on soft beds. Science, 267(5194), 80-81. doi: 10.1126/science.267. 5194.80

Iverson NR, Jansson P and Hooke RL (1994) In-situ measurement of the strength of deforming subglacial till. Journal of Glaciology 40(136), 497503. doi: $10.3189 / \mathrm{S} 0022143000012375$

Jóhannesson T (2002) Propagation of a subglacial flood wave during the initiation of a jökulhlaup. Hydrological Sciences Journal 47(3), 417-434. doi: $10.1080 / 02626660209492944$

Kamb B (1987) Glacier surge mechanism based on linked-cavity configuration of the basal water conduit system. Journal of Geophysical Research 92(B9), 9083-9100. doi: 10.1029/JB092iB09p09083

Kamb B (2001) Basal zone of the West Antarctic ice streams and its role in lubrication of their rapid motion. In: The West Antarctic Ice Sheet: Behavior and Environment, 157-199. American Geophysical Union (doi: 10.1029/AR077p0157).

Kamb B and Engelhardt H (1987) Waves of accelerated motion in a glacier approaching surge: the mini-surges of Variegated Glacier, Alaska, U.S.A. Journal of Glaciology 33(113), 27-46. doi: 10.3189/S0022143000005311

Knight PG, Waller RI, Patterson CJ, Jones AP and Robinson ZP (2002) Discharge of debris from ice at the margin of the Greenland ice sheet. Journal of Glaciology 48(161), 192-198. doi: 10.3189/172756502781831359

Kulessa B and Hubbard B (1997) Interpretation of borehole impulse tests at Haut Glacier d'Arolla, Switzerland. Annals of Glaciology 24, 397-402. doi: $10.3189 / \mathrm{S} 0260305500012507$

Kulessa B, Hubbard B, Williamson $M$ and Brown GH (2005) Hydrogeological analysis of slug tests in glacier boreholes. Journal of Glaciology 51(173), 269-280. doi: 10.3189/172756505781829458

Kulessa B and Murray T (2003) Slug-test derived differences in bed hydraulic properties between a surge-type and a non-surge-type Svalbard glacier. Annals of Glaciology 36, 103-109. doi: 10.3189/172756403781816257

Law R and 11 others (2021) Thermodynamics of a fast-moving greenlandic outlet glacier revealed by fiber-optic distributed temperature sensing. Science Advances 7(20). doi: 10.1126/sciadv.abe7136

Lefeuvre PM and 5 others (2018) Stress redistribution explains anti-correlated subglacial pressure variations. Frontiers in Earth Science 5, 110. doi: 10. 3389/feart.2017.00110

Lefeuvre PM, Jackson M, Lappegard G and Hagen JO (2015) Interannual variability of glacier basal pressure from a 20 year record. Annals of Glaciology 56(70), 33-44. doi: 10.3189/2015AoG70A019

Lingle CS and Brown TJ (1987) A subglacial aquifer bed model and water pressure dependent basal sliding relationship for a West Antarctic ice 
stream. In CJ Van der Veen and J Oerlemans (eds.), Dynamics of the West Antarctic Ice Sheet, 249-285, Springer Netherlands, Dordrecht.

Lüthi M (1999) Experimental and numerical investigation of a firn covered cold glacier and a polythermal ice stream: case studies at Colle Gniffetti and Jakobshavn Isbræ. Ph.D. thesis, Swiss Federal Institute of Technology Zurich.

Lüthi M, Fahnestock M and Truffer M (2009) Calving icebergs indicate a thick layer of temperate ice at the base of Jakobshavn Isbræ, Greenland. Journal of Glaciology 55(191), 563-566. doi: 10.3189/002214309788816650

Makinson K and Anker P (2014) The BAS ice-shelf hot-water drill: design, methods and tools. Annals of Glaciology 55(68), 44-52. doi: 10.3189/ 2014AoG68A030

Meierbachtol T, Harper J, Humphrey N and Wright $\mathbf{P}$ (2016) Mechanical forcing of water pressure in a hydraulically isolated reach beneath Western Greenland's ablation zone. Annals of Glaciology 52(72), 62-70. doi: 10.1017/aog.2016.5

Murray T (1997) Assessing the paradigm shift: deformable glacier beds. Quaternary Science Reviews 16(9), 995-1016. ISSN 0277-3791. doi:10. 1016/S0277-3791(97)00030-9).

Murray T and Clarke G (1995) Black-box modelling of the subglacial water system. Journal of Geophysical Research 100, 10231-10245. doi: 10.1029/ 95JB00671

Ng F (2000) Canals under sediment-based ice sheets. Annals of Glaciology 30 (1), 146-152. doi: 10.3189/172756400781820633

Nye J (1952) The mechanics of glacier flow. Journal of Glaciology 2(11), 52-53.

Ó'Cofaigh C and 6 others (2013) Glacimarine lithofacies, provenance and depositional processes on a West Greenland trough-mouth fan. Journal of Quaternary Science 28(1), 13-26. doi: 10.1002/jqs.2569

Porter C and 27 others (2018) ArcticDEM, Harvard Dataverse, V1 (doi: 10.7910/DVN/OHHUKH).

Rada C and Schoof C (2018) Channelized, distributed, and disconnected: subglacial drainage under a valley glacier in the Yukon. The Cryosphere 12, 2609-2636. doi: 10.5194/tc-12-2609-2018

Reeh N, Christensen EL, Mayer C and Olesen OB (2003) Tidal bending of glaciers: a linear viscoelastic approach. Annals of Glaciology 37(7), 83-89. doi: doi:10.3189/172756403781815663

Rempel AW (2008) A theory for ice-till interactions and sediment entrainment beneath glaciers. Journal of Geophysical Research: Earth Surface 113 (F1). doi: 10.1029/2007JF000870

Rignot E, Box JE, Burgess E and Hanna E (2008) Mass balance of the Greenland ice sheet from 1958 to 2007. Geophysical Research Letters 35 (20). doi: 10.1029/2008GL035417.

Robin G de Q (1976) Is the basal ice of a temperate glacier at the pressure melting point?. Journal of Glaciology 16(74), 183-196. doi: 10.3189/ S002214300003152X

Ronayne MJ, Houghton TB and Stednick JD (2012) Field characterization of hydraulic conductivity in a heterogeneous alpine glacial till. Journal of Hydrology 458-459, 103-109. doi: 10.1016/j.jhydrol.2012.06.036

Röthlisberger H (1972) Water pressure in intra- and subglacial channels. Journal of Glaciology 11(62), 177-203. doi: 10.3189/\$0022143000022188

Ryser C and 7 others (2014) Caterpillar-like ice motion in the ablation zone of the Greenland ice sheet. Journal of Geophysical Research: Earth Surface 119 (10), 2258-2271.

Schoof C (2010) Ice-sheet acceleration driven by melt water supply variability. Nature 468, 803-806. doi: 10.1038/nature09618

Schoof C, Hewitt IJ and Werder MA (2012) Flotation and free surface flow in a model for subglacial drainage. Part 1. Distributed drainage. Journal of Fluid Mechanics 702, 126. doi: 10.1017/jfm.2012.165

Sinha NK (1978) Short-term rheology of polycrystalline ice. Journal of Glaciology 21(85), 457-474. doi: 10.3189/S002214300003361X
Smart CC (1996) Statistical evaluation of glacier boreholes as indicators of basal drainage systems. Hydrological Processes 10(4), 599-613. doi: 10. 1002/(SICI) 1099-1085(199604)10:4<599::AID-HYP394>3.0.CO;2-8

Sole A and 6 others (2013) Winter motion mediates dynamic response of the Greenland Ice Sheet to warmer summers. Geophysical Research Letters 40, 3940-3944. doi: 10.1002/grl.507764

Stevens LA and 7 others (2015) Greenland supraglacial lake drainages triggered by hydrologically induced basal slip. Nature 522(7554), 73-76. doi: 10.1038/nature14480

Stone D and Clarke G (1993) Estimation of subglacial hydraulic properties from induced changes in basal water pressure: a theoretical framework for borehole-response tests. Journal of Glaciology 39(132), 327-340. doi: $10.3189 /$ S0022143000015999

Stone DB, Clarke GKC and Ellis RG (1997) Inversion of borehole-response test data for estimation of subglacial hydraulic properties. Journal of Glaciology 43(143), 103-113. doi: 10.3189/\$0022143000002860

Sugiyama S, Bauder A, Huss M, Riesen P and Funk M (2008) Triggering and drainage mechanisms of the 2004 glacier-dammed lake outburst in Gornergletscher, Switzerland. Journal of Geophysical Research 113, F04019. doi: 10.1029/2007JF000920

Tedstone AJ and 5 others (2015) Decadal slowdown of a land-terminating sector of the Greenland Ice Sheet despite warming. Nature 526(7575), 692-695. doi: 10.1038/nature 15722

Theis CV (1935) The relation between the lowering of the piezometric surface and the rate and duration of discharge of a well using ground-water storage. Eos, Transactions American Geophysical Union 16(2), 519-524. doi: 10. 1029/TR016i002p00519

Thiem G (1906) Hydrological methods, PhD Thesis. Royal Technical University of Stuttgart, Germany.

Tsai V and Rice J (2010) A model for turbulent hydraulic fracture and application to crack propagation at glacier beds. Journal of Geophysical Research 115, F03007. doi: 10.1029/2009JF001474

Tsai VC and Rice JR (2012) Modeling turbulent hydraulic fracture near a free surface. Journal of Applied Mechanics 79(3), 031003. doi: 10.1115/1. 4005879.

Tulaczyk S, Kamb WB and Engelhardt HF (2000) Basal mechanics of Ice Stream B, West Antarctica: 1. Till mechanics. Journal of Geophysical Research: Solid Earth 105(B1), 463-481. doi: 10.1029/1999JB900329

Waddington BS and Clarke GK (1995) Hydraulic properties of subglacial sediment determined from the mechanical response of water-filled boreholes. Journal of Glaciology 41(137), 112-124. doi: 10.3189/ S0022143000017810

Walder J and Fowler A (1994) Channelized subglacial drainage over a deformable bed. Journal of Glaciology 40(134), 3-15. doi: 10.3189/ S0022143000003750

Walter F, Chaput J and Luthi M (2014) Thick sediments beneath Greenland's ablation zone and their potential role in future ice sheet dynamics. Geology 42(6), 487-490. doi: 10.1130/G35492.1

Weertman J (1970) A method for setting a lower limit on the water layer thickness at the bottom of an ice sheet from the time required for upwelling of water into a borehole. IAHS Publ. 86, 69-73.

Weertman J (1972) General theory of water flow at the base of a glacier or ice sheet. Reviews of Geophysics 10(1), 287-333. doi: 10.1029/RG010i001p00287

Werder MA, Hewitt IJ, Schoof CG and Flowers GE (2013) Modeling channelized and distributed subglacial drainage in two dimensions. Journal of Geophysical Research: Earth Surface 118(4), 2140-2158. doi: 10.1002/jgrf. 20146

Young TJ and 11 others (2019) Physical conditions of fast glacier flow: 3. Seasonally-evolving ice deformation on Store Glacier, West Greenland. Journal of Geophysical Research: Earth Surface 124(1), 245-267. doi: 10. 1029/2018JF004821 


\section{Appendix A. List of symbols}

$\alpha$

$\beta_{\mathrm{w}} \quad$ Water compressibility $\left(5.1 \times 10^{-10} \mathrm{~Pa}^{-1}\right)$

$\gamma \quad$ Clausius-Clapeyron constant $\left(9.14 \times 10^{-8} \mathrm{~K} \mathrm{~Pa}^{-1}\right)$

$\delta \quad$ Gap width (m)

$\eta_{\mathrm{i}} \quad$ Effective ice viscosity $\left(\mathrm{Pa} \mathrm{s}^{-1}\right)$

$\eta_{\mathrm{w}} \quad$ Water viscosity at $0^{\circ} \mathrm{C}(0.0018 \mathrm{~Pa} \mathrm{~s})$

$\rho_{\mathrm{i}} \quad$ Ice density $\left(910 \pm 10 \mathrm{~kg} \mathrm{~m}^{-3}\right)$

$\rho_{\mathrm{w}} \quad$ Water density at $0^{\circ} \mathrm{C}\left(999.8 \mathrm{~kg} \mathrm{~m}^{-3}\right)$

$\rho_{\mathrm{d}} \quad$ Hose density $\left(\mathrm{kg} \mathrm{m}^{-3}\right)$

$\tau_{\mathrm{e}} \quad$ Effective stress $(\mathrm{Pa})$

$\phi \quad$ Areal fraction of the bed covered by gap

A Rate factor in Glen's flow law $\left(\mathrm{Pa}^{-3} \mathrm{~s}^{-1}\right)$

$b \quad$ Sediment thickness (m)

$B \quad$ Bending modulus of the ice $\left(\mathrm{Pa} \mathrm{m}^{3}\right)$

D Time constant (s)

E Elastic modulus of ice $(9.3 \mathrm{GPa})$

$f \quad$ Shape factor

$f_{\mathrm{D}} \quad$ Frictional drag coefficient

$F \quad$ Force on the drill tower (N)

$g \quad$ Gravitational acceleration $\left(9.81 \mathrm{~m} \mathrm{~s}^{-2}\right)$

$h \quad$ Hydraulic head (m)

$h_{0} \quad$ Reference hydraulic head (m)

$H_{\mathrm{i}} \quad$ Ice thickness (m)

$H_{\mathrm{w}} \quad$ Water height $(\mathrm{m})$

$K \quad$ Hydraulic conductivity $\left(\mathrm{m} \mathrm{s}^{-1}\right)$

$M \quad$ Sediment stiffness ( $\mathrm{p}$-wave modulus) $(\mathrm{Pa})$

$n \quad$ Exponent in Glen's flow law (3)

$N \quad$ Effective pressure $(\mathrm{Pa})$

$p_{\mathrm{i}} \quad$ Ice overburden pressure $(\mathrm{Pa})$

$p_{\mathrm{w}} \quad$ Subglacial water pressure $(\mathrm{Pa})$

$p_{\text {tr }} \quad$ Triple point pressure of water $(611.73 \mathrm{~Pa})$

$Q \quad$ Volumetric flux $\left(\mathrm{m}^{3} \mathrm{~s}^{-1}\right)$

$r \quad$ Radial distance $(\mathrm{m})$

$r_{\mathrm{d}} \quad$ External hose radius $(0.015 \mathrm{~m})$

$r_{0} \quad$ Borehole radius at base $(\mathrm{m})$

$r_{\mathrm{s}} \quad$ Borehole radius at near-surface $(\mathrm{m})$

$R \quad$ Radius of influence (m)

Re Reynolds number

$s \quad$ Recharge $\left(s=h-h_{0}\right)(\mathrm{m})$

$s_{0} \quad$ Reference recharge $(\mathrm{m})$

$S \quad$ Storage coefficient $(\mathrm{m})$

$t \quad$ Time (s)

$t_{\mathrm{M}} \quad$ Maxwell time (s)

$T \quad$ Hydraulic transmissivity $\left(\mathrm{m}^{2} \mathrm{~s}^{-1}\right)$

$T_{\mathrm{m}} \quad$ Melting temperature of ice $\left({ }^{\circ} \mathrm{C}\right)$

$T_{\mathrm{tr}} \quad$ Triple point temperature of water $(273.16 \mathrm{~K})$

$U_{\mathrm{d}} \quad$ Drill velocity $\left(\mathrm{m} \mathrm{min}^{-1}\right)$

$U_{\mathrm{w}} \quad$ Water velocity $\left(\mathrm{m} \mathrm{s}^{-1}\right)$

$V \quad$ Volume $\left(\mathrm{m}^{3}\right)$

$W(u) \quad$ Well function

$z \quad$ Orthometric height $(\mathrm{m})$

\section{Appendix B. Borehole radius}

As the hose radius $\left(r_{\mathrm{d}}\right)$ and speed $\left(U_{\mathrm{d}}\right)$ are known, the differential rate of change in hydraulic head below and above the water line during the $\mathrm{BH} 19 \mathrm{~g}$ (e) pumping test allows the borehole radius at the water line $\left(r_{\mathrm{s}}\right)$ to be determined as follows. The total volumetric flux of water stored within the borehole when the drill hose was below the water line during PT2 is $Q_{\mathrm{b} 2}=Q_{\mathrm{s} 2}+Q_{\mathrm{d} 2}$, or alternatively

$$
Q_{\mathrm{b} 2}=\left(\pi r_{\mathrm{s}}^{2}-\pi r_{\mathrm{d}}^{2}\right) \frac{\mathrm{d} h_{2}}{\mathrm{~d} t}+\pi r_{\mathrm{d}}^{2} U_{\mathrm{d}}
$$

where the numeric subscript indicates the period. Similarly the borehole
Table B1. Borehole radii at the time of borehole breakthrough predicted using the model of Greenler et al. (2014) over ten depth intervals ranging from the ice surface to the ice-sediment interface at a depth below the ice surface corresponding to the ice thickness $\left(H_{\mathrm{i}}\right)$

\begin{tabular}{lccc}
\hline & \multicolumn{3}{c}{ Radius $(\mathrm{m})$} \\
\cline { 2 - 4 } Depth $(\mathrm{m})$ & $\mathrm{BH} 19 \mathrm{c}$ & BH19e & BH19g \\
\hline $0-100$ & 0.07 & 0.07 & 0.07 \\
$101-200$ & 0.05 & 0.06 & 0.05 \\
$201-300$ & 0.06 & 0.07 & 0.05 \\
$301-400$ & 0.06 & 0.07 & 0.06 \\
$401-500$ & 0.07 & 0.07 & 0.06 \\
$501-600$ & 0.07 & 0.07 & 0.06 \\
$601-700$ & 0.07 & 0.07 & 0.07 \\
$701-800$ & 0.08 & 0.08 & 0.08 \\
$801-900$ & 0.10 & 0.10 & 0.11 \\
$901-H_{\mathrm{i}}$ & 0.10 & 0.10 & 0.11 \\
Mean & 0.07 & 0.08 & 0.07 \\
\hline
\end{tabular}

storage flux with the drill stem above the water line during PT3 is

$$
Q_{b 3}=\pi r_{\mathrm{s}}^{2} \frac{\mathrm{d} h_{3}}{\mathrm{~d} t}
$$

Assuming water input $\left(Q_{\mathrm{i}}\right)$ and output $\left(Q_{\mathrm{o}}\right)$ were constant at the transition from PT2 to PT3

$$
Q_{\mathrm{b} 2}=Q_{\mathrm{b} 3} \text {. }
$$

Therefore equating fluxes gives

$$
\left(\pi r_{\mathrm{s}}^{2}-\pi r_{\mathrm{d}}^{2}\right) \frac{\mathrm{d} h_{2}}{\mathrm{~d} t}+\pi r_{\mathrm{d}}^{2} U_{\mathrm{d}}=\pi r_{\mathrm{s}}^{2} \frac{\mathrm{d} h_{3}}{\mathrm{~d} t} .
$$

Expanding on the left-hand side gives

$$
\pi r_{\mathrm{s}}^{2} \frac{\mathrm{d} h_{2}}{\mathrm{~d} t}-\pi r_{\mathrm{d}}^{2} \frac{\mathrm{d} h_{2}}{\mathrm{~d} t}+\pi r_{\mathrm{d}}^{2} U_{\mathrm{d}}=\pi r_{\mathrm{s}}^{2} \frac{\mathrm{d} h_{3}}{\mathrm{~d} t} .
$$

Rearranging gives

$$
\pi r_{\mathrm{s}}^{2} \frac{\mathrm{d} h_{3}}{\mathrm{~d} t}-\pi r_{\mathrm{s}}^{2} \frac{\mathrm{d} h_{2}}{\mathrm{~d} t}=\pi r_{\mathrm{d}}^{2} U_{\mathrm{d}}-\pi r_{\mathrm{d}}^{2} \frac{\mathrm{d} h_{2}}{\mathrm{~d} t}
$$

and factorising gives

$$
\pi r_{\mathrm{s}}^{2}\left(\frac{\mathrm{d} h_{3}}{\mathrm{~d} t}-\frac{\mathrm{d} h_{2}}{\mathrm{~d} t}\right)=\pi r_{\mathrm{d}}^{2}\left(U_{\mathrm{d}}-\frac{\mathrm{d} h_{2}}{\mathrm{~d} t}\right)
$$

which we rearrange to find

$$
r_{\mathrm{s}}=\left[\frac{r_{\mathrm{d}}^{2}\left(U_{\mathrm{d}}-\frac{\mathrm{d} h_{2}}{\mathrm{~d} t}\right)}{\frac{\mathrm{d} h_{3}}{\mathrm{~d} t}-\frac{\mathrm{d} h_{2}}{\mathrm{~d} t}}\right]^{1 / 2}
$$

Using Eqn (B8), the known hose radius $\left(r_{\mathrm{d}}=0.015 \mathrm{~m}\right)$, the measured mean drill speed during PT2 $\left(\bar{U}_{\mathrm{d}}=8.82 \mathrm{~min}^{-1}\right)$, and the rate of change in hydraulic head during PT2 $\left(\mathrm{d} h_{2} / \mathrm{d} t=1.36 \mathrm{~m} \mathrm{~h}^{-1}\right)$ and PT3 $\left(\mathrm{d} h_{3} / \mathrm{d} t=7.40 \mathrm{~m} \mathrm{~h}^{-1}\right)$, gives a borehole radius at the water-line $r_{\mathrm{s}}=0.14 \mathrm{~m}$. This estimate is double that of the borehole model $\left(r_{\mathrm{s}}=0.07 \mathrm{~m}\right.$; Table $\left.\mathrm{B} 1\right)$, but consistent with the borehole radius measured at the surface.

Measurements were not made of $\mathrm{BH} 19 \mathrm{~g}$ but $\mathrm{BH} 19 \mathrm{e}$ had a radius at the surface of $0.17 \mathrm{~m}$. As the pumping test period was not recorded in $\mathrm{BH} 19 \mathrm{c}$ and $\mathrm{BH} 19 \mathrm{e}$ we assume that their near-surface radius was the same as $\mathrm{BH} 19 \mathrm{~g}$ : that is, we assume $r_{\mathrm{s}}=0.14 \mathrm{~m}$ for all response tests. Near-surface borehole radii larger than predicted by the Greenler and others (2014) model could be explained by turbulent heat exchange from warm upwelling water. Laminar flow is specified in the model. The effect of turbulent heat exchange on borehole radius would decrease with depth so the model should perform better near the base. With no better estimate available, we therefore use the model output for the borehole radius at the base $\left(r_{0}\right.$; Table B1). 


\section{Appendix C. Elastic response of ice to borehole breakthrough}

Here we consider the relative importance of viscous and elastic deformation in the response of the ice sheet at site R30 to borehole breakthrough forcing by calculating the Maxwell relaxation time

$$
t_{\mathrm{M}}=\frac{\eta_{\mathrm{i}}}{E}
$$

where $E=9.3 \mathrm{GPa}$ is the elastic modulus for ice (Sinha, 1978), and $\eta_{\mathrm{i}}$ is the effective ice viscosity. The effective viscosity can be given as

$$
\eta_{\mathrm{i}}=\frac{1}{2 A}\left(\tau_{\mathrm{e}}^{2}\right)^{\frac{1-n}{2}}
$$

where $A$ and $n=3$ are the rate factor and exponent in Glen's flow law, and $\tau_{\mathrm{e}}$ is the effective stress (Hutter, 1983). For simplicity, we estimate the effective stress

$$
\tau_{\mathrm{e}}=f \rho_{\mathrm{i}} g H_{\mathrm{i}} \sin \alpha,
$$

where, for site R30, $f \approx 0.75$ is the shape factor representing the proportion of driving stress supported by basal drag (Nye, 1952). Using Eqn (C3), the effective stress at site R30 is $121 \mathrm{kPa}$. We assume that viscous deformation will be greatest within the basal temperate ice layer and therefore use upper and lower limits of $A$ for temperate ice of $5.5-2.4 \times 10^{-24} \mathrm{~Pa}^{-3} \mathrm{~s}^{-1}$ (Cuffey and Paterson, 2010). With these values the effective viscosity is $6.2-14.2 \times 10^{-12} \mathrm{~Pa} \mathrm{~s}^{-1}$, and the Maxwell time is $11-25 \mathrm{~min}$. Hence, assuming elastic ice rheology at site R30 is reasonable during the initial stages of gap opening. Over the time scales relevant to pumping and recovery tests viscous deformation should not be neglected and a viscoelastic model (e.g., Reeh and others, 2003) would be more appropriate. Note, however, that the rheology of the ice actually drops out of the asymptotic solution of the Hewitt and others (2018) model in Eqn (22), and so incorporating viscous deformation may not have a large effect on the predictions of transmissivity from that model.

\section{Appendix D. Transmissivity from time constant}

The hydraulic transmissivity $\left(T_{\mathrm{g}}\right)$ of a porous medium equivalent to a gap of uniform width $\delta$ is given by de Marsily (1986) as

$$
T_{\mathrm{g}}=\frac{\phi \delta^{3} \rho_{\mathrm{w}} g}{12 \eta_{\mathrm{w}}}
$$

The time constant $D$ is given by

$$
D=\frac{6 \eta_{\mathrm{w}} r_{\mathrm{s}}^{2}}{\delta^{3} \rho_{\mathrm{w}} g} \ln \frac{R}{r_{0}},
$$

which is Eqn (7a) of Weertman (1970) and Eqn (9) of Engelhardt and Kamb (1997). Combining Eqns (D1) and (D2) as follows allows the hydraulic transmissivity to be approximated from the time constant $D$. Inserting $\phi$ and then multiplying both sides of Eqn (D2) by two gives

$$
2 D=\frac{12 \eta_{\mathrm{w}} r_{\mathrm{s}}^{2}}{\phi \delta^{3} \rho_{\mathrm{w}} g} \ln \frac{R}{r_{0}}
$$

This permits simplification by inserting the inverse of Eqn (D1) into Eqn (D3)

$$
2 D=\frac{1}{T_{\mathrm{g}}} r_{\mathrm{s}}^{2} \ln \frac{R}{r_{0}}
$$

Multiplying both sides by $T_{\mathrm{g}}$ gives

$$
2 D T_{\mathrm{g}}=r_{\mathrm{s}}^{2} \ln \frac{R}{r_{0}}
$$

And further rearranging gives

$$
T_{\mathrm{g}}=\frac{r_{\mathrm{s}}^{2}}{2 D} \ln \frac{R}{r_{0}}
$$

which is Eqn (8.7) of Lüthi (1999) and Eqn (27) of this paper. 